\title{
Research Square \\ Deformation Failure and Gas Seepage of Raw Coal in Alternate Loading and Unloading by Stages
}

\section{Bang-an Zhang}

Chongqing University

Yang yushun ( $\nabla$ cqyysh@126.com )

Huaiyin Institute of Technology https://orcid.org/0000-0002-9318-339X

\section{Research Article}

Keywords: alternate loading-unloading, raw coal, deformation failure, gas seepage, strain rate

Posted Date: June 1st, 2021

DOl: https://doi.org/10.21203/rs.3.rs-510022/v1

License: (c) (i) This work is licensed under a Creative Commons Attribution 4.0 International License. Read Full License 
2 Deformation failure and gas seepage of raw coal in alternate loading 3 and unloading by stages

Bang-an Zhang ${ }^{1}$, Yu-shun Yang ${ }^{2,3}$

1 School of Resources and Safety Engineering, Chongqing University, Chongqing 400044, China;

2 State and Local Joint Engineering Laboratory for Gas Drainage \& Ground Control of Deep Mines, Henan Polytechnic University

3 Faculty of Architecture and Civil Engineering, Huaiyin Institute of Technology, Jiangsu 223001, China

* Correspondence: cqyysh@126.com

Abstract: In this paper, the cyclic loading and unloading confining pressure tests of raw coal samples were carried out by using the "Triaxial seepage test device of thermal fluid solid of coal and rock" developed by Chongqing University. The conclusions are as follows: (1) The axial strain change rate $\varepsilon 1^{\prime}$, the radial strain change rate $\varepsilon 3^{\prime}$ and the permeability change rate $k^{\prime}$ under unit stress state are used to represent the sensitivity of axial stress and confining pressure to deformation and permeability characteristics of samples under unit stress state. (2) At the initial stage of unloading the confining pressure, the confining pressure has a greater influence on the permeability of the sample. At the initial stage of loading confining pressure, the confining pressure has a greater influence on the radial strain of the specimen. During the subsequent loading and unloading process, the confining pressure of loading and unloading has a greater influence on the permeability of the sample, and a smaller influence on the axial strain. The loading axial stress has a greater influence on the axial strain of the sample, and a smaller influence on the permeability of the sample. (3) When the axial stress is constant, the increase range of sample permeability increases with the increase of unloading confining pressure range, and the decreasing range of sample permeability increases with the increase of loading confining pressure range, and the increase range of sample permeability under unloading confining pressure is higher than that under increasing confining pressure. (4) In the process of loading axial stress and loading confining pressure, the permeability of samples decreases nonlinearly with the increase of principal stress difference, while the permeability of samples increases nonlinearly with the decrease of principal stress difference in the process of unloading confining pressure.

\section{Introduction}

The mining of underground coal resources breaks the original stress balance, which will inevitably cause the redistribution of the internal stress field of the surrounding coal and rock masses, thus making the coal and rock masses in front of the work face a complex loading and unloading process, which is often accompanied by surrounding rocks. The conversion of energy within the body, especially the outflow of gas, has always threatened the safety of underground production. Once these disasters occur, they will cause huge economic losses to the mine and seriously threaten the lives of mine workers.

At present, scholars at home and abroad have carried out many studies on the permeability of coal and rock under loading and unloading conditions, and have achieved many beneficial results. Some scholars use coal briquette to carry out research ( $\mathrm{Li}$, et al. 2010; Xu, et al. 2014; Wang, et al. 2016). Briquette has 
strong repeatability. However, this is quite different from the complex conditions on site, and the test results cannot be applied well on site. Therefore, many scholars have used raw coal samples to carry out related research. Liu (2019) carried out research on the evolution of coal permeability under the control of cyclic loading, which has theoretical support for explaining the anisotropic characteristics of coal permeability under complex stress fields. Jia et al. (2020) comparatively studied the permeability response characteristics of coal briquette samples and raw coal samples under the influence of mining. Xiao et al. (2012) studied the law of gas migration in the process of coal and rock deformation and fracture. Xu et al. (2012) carried out coal loading and unloading tests using the stress control method of adding axial pressure and unloading confining pressure, and analyzed the evolution law of coal and rock deformation characteristics and permeability characteristics under loading and unloading conditions. Yuan and Zhang (2017 revealed the deformation and seepage characteristics of coal samples under the staged unloading confining pressure through gas seepage tests of briquette under different paths. Li et al. (2019) conducted isotherm adsorption tests and seepage tests with increased pore pressure under different water-bearing conditions, constructed a permeability model considering the influence of water, and then analyzed the changes in coal and rock adsorption and seepage under different water-bearing conditions. Zhang et al. (2017) simulated coal seam excavation by unloading confining pressure, carried out a triaxial seepage test of gas-containing raw coal, and clarified the three-stage characteristics of gas seepage characteristics of raw coal. Yin et al. (2018) developed the mechanical properties and permeability evolution of raw coal under true triaxial loading and unloading stress paths. Duan et al. (2018) conducted a staged loading-unloading test of gas-containing raw coal, analyzed and discussed the deformation, permeability characteristics and energy consumption characteristics of coal and rock, and established a damage variable equation based on the energy consumption characteristics. Zhao et al. (2019) carried out gas flow characteristics tests under different conditions on pure coal samples, samples containing single-layer gangue, and samples containing two-layer gangue. Zhu et al. (2020) studied the influence mechanism of gas pressure and mining stress on coal and rock deformation and gas flow. Zhao et al. (2016) analyzed and studied the mechanical properties and seepage evolution laws of raw coal under different loading and unloading rates. Liu et al. (2014) conducted an experimental study on the effect of helium on the permeability of coal samples under the condition of changing the effective stress (4MPa 12MPa), and showed that the permeability of the sample decreased exponentially with the increase of effective stress. Xin et al. (2018) conducted mechanical and permeability tests of gas-bearing coal under different stress paths (conventional triaxial compression, staged variable speed triaxial compression, unloading of confining pressure and staged variable speed unloading of confining pressure). Zuo et al. (2016) studied the effect of effective stress and gas slippage effect on the permeability of coal samples under cyclic loading conditions, and believed that the slippage effect has a significant impact on the permeability of coal samples, especially in the low pore pressure range. The slippage effect is greater than the effective 
stress. Ye et al. (2017) simulated the response characteristics of pore pressure to the permeability of raw coal under different loading and unloading paths of ground stress. Ju et al. (2017) conducted the methane permeability characteristics of fractured coal under different excavation stress paths and its dependence on the internal fracture network of fractured coal.

Previous studies mostly studied the deformation and permeability characteristics of coal and rock

80 samples by loading and unloading axial pressure and confining pressure, and did not focus on the 81 characteristics of grading, discontinuous, and variable loading and unloading strengths of the coal seam 82 under actual mining conditions. Related research. In order to more realistically simulate the changes in the 83 pressure of the coal seam during mining, and to further understand the deformation and failure of coal 84 samples and the law of gas seepage under the conditions of staged loading axial pressure and loading and 85 unloading confining pressure, the classification under the same loading rate was carried out this time. 86 Research on the influence of loading axial pressure and loading and unloading confining pressure on the deformation and failure of gas-bearing coal and gas seepage characteristics.

\section{$88 \quad 2$ Test device and scheme}

\subsection{Test device}

The test device is a coal rock thermal fluid solid coupling triaxial servo seepage system developed by

91 Chongqing University, as shown in Figure 1. The device consists of stress loading system, specimen clamping 92 system, pore pressure control system, data acquisition system, vacuum extraction system and constant 93 temperature water bath control system. It can simulate the gas permeability characteristics of coal samples 94 under different pore pressure, confining pressure and temperature. The maximum axial load is $1000 \mathrm{kN}$, the 95 radial confining pressure can be added to $60 \mathrm{MPa}$, and the maximum gas pressure can be $6 \mathrm{MPa}$. The maximum 96 axial deformation is $60 \mathrm{~mm}$ and the radial deformation is $6 \mathrm{~mm}$. The deformation accuracy is controlled within 97 $\pm 1 \%$. 

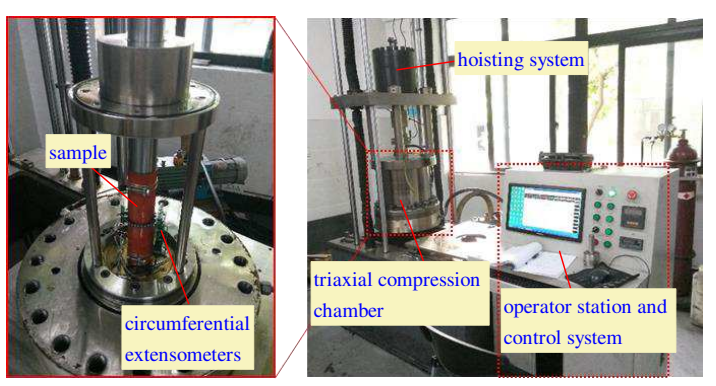

Fig. 1 Tri-axial stress thermal-hydrological-mechanical Coal Gas Permeameter

Assuming that the gas flow in the coal sample conforms to Darcy's law, the permeability value can be obtained according to the gas pressure at both ends of the coal sample, gas flow rate, coal sample size and other parameters (Xu, et al. 2012; Zhang, et al. 2017):

$$
k=\frac{2 \mu P_{2} Q L}{A\left(P_{1}^{2}-P_{2}^{2}\right)}
$$

Where, $k$ is permeability $(\mathrm{mD}) ; \mu$ is gas dynamic viscosity coefficient at measured temperature, taking $1.08 \times 10^{-5} \mathrm{pa} \cdot \mathrm{s} ; L$ is sample length $(\mathrm{cm}) ; A$ is sample cross-sectional area $\left(\mathrm{cm}^{2}\right) ; P_{1}$ is gas inlet pressure $(\mathrm{MPa})$; $P_{2}$ is gas outlet pressure (MPa); $Q$ is gas flow under standard condition $\left(\mathrm{cm}^{3} / \mathrm{s}\right)$.

\subsection{Coal sample preparation}

The test samples are taken from the No. 2+3\# coal seam of Shanmushu Coal Mine, which is a coal and gas outburst coal seam. The gas pressure of the coal seam is $0.8 \mathrm{MPa} 1.7 \mathrm{MPa}$, the average is $1.32 \mathrm{MPa}$, the inclination angle of the coal seam is $2^{\circ} \sim 6^{\circ}$, and the average thickness is about $3.1 \mathrm{~m}$. Select lump coal with a size greater than $200 \mathrm{~mm} \times 200 \mathrm{~mm} \times 200 \mathrm{~mm}$ on site, seal the lump coal with plastic wrap and transport it back to the laboratory, and drill it in accordance with the "Method for Determination of Physical and Mechanical Properties of Coal and Rocks" (GB/T23561.7-2009) Processed into a standard cylindrical raw coal sample with a size of $\emptyset 50 \mathrm{~mm} \times 100 \mathrm{~mm}$, the samples are shown in Figure 2.

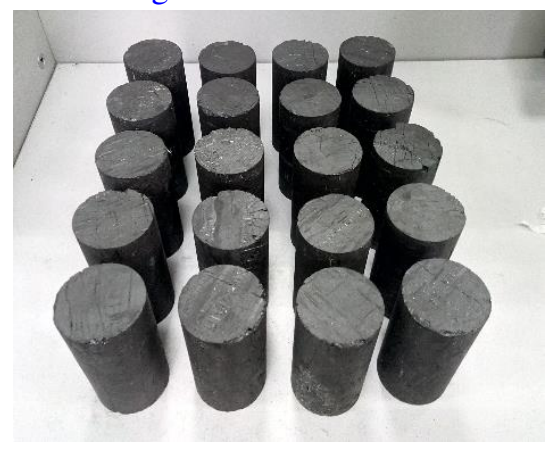

Fig. 2 Raw coal sample

\subsection{Test plan}

This test mainly studies the permeability evolution law of raw coal samples under alternately staged loading axial stress and loading and unloading confining pressure. The details are as follows: (1) First, load the axial stress and confining pressure of the raw coal sample at the same rate $\sigma_{1}=\sigma_{3}=7.0 \mathrm{MPa}$, vacuumize the coal sample, introduce $99.99 \%$ methane gas, and adjust the inlet pressure to $\mathrm{p}_{1}=2.0 \mathrm{MPa}$, and make the coal absorb 
123 gas for 24 h. (2) Open the valve at the gas outlet side, and perform alternate axial stress loading and unloading

124 confining pressure tests after the flow is stable. The axial stress loading rate is $0.05 \mathrm{kN} / \mathrm{s}$, and the confining

125 pressure loading and unloading rate is $0.02 \mathrm{MPa} / \mathrm{s}$. (3) After the alternate loading and unloading of axial stress

126 and confining pressure is completed, the confining pressure shall be kept constant, and the axial stress shall be

127 loaded at a rate of $0.1 \mathrm{~mm} / \mathrm{min}$ under displacement control until the specimen is broken. At the end of the test,

128 the coal sample was replaced and the confining pressure was changed to 6.0 $\mathrm{MPa}, 7.0 \mathrm{MPa}, 8.0 \mathrm{MPa}$ and 9.0

129 MPa respectively. During the loading and unloading process of axial stress and confining pressure, each level is

130 maintained for five minutes. The loading and unloading steps of each sample are as follows:

131 a. Sample a1,the loading and unloading step are (1) (10)

\begin{tabular}{|c|c|c|c|c|c|c|c|c|c|c|c|c|c|}
\hline$\sigma_{1} / \mathrm{MPa}$ & 7.0 & & 7.0 & $\begin{array}{l}\text { (2) } \\
\rightarrow\end{array}$ & 10.63 & $\begin{array}{l}\text { (4) } \\
\rightarrow\end{array}$ & 14.25 & $\begin{array}{l}\text { (6) } \\
\rightarrow\end{array}$ & 17.88 & $\begin{array}{l}\text { (8) } \\
\rightarrow\end{array}$ & 21.5 & $\begin{array}{l}\text { (10) } \\
\rightarrow\end{array}$ & peak intensity \\
\hline$\sigma_{3} / \mathrm{MPa}$ & 7.0 & $\begin{array}{l}\text { (1) } \\
\rightarrow\end{array}$ & 6.0 & $\begin{array}{l}\text { (3) } \\
\rightarrow\end{array}$ & 4.0 & $\begin{array}{l}\text { (5) } \\
\rightarrow\end{array}$ & 6.0 & $\begin{array}{l}\text { (7) } \\
\rightarrow\end{array}$ & 4.0 & $\begin{array}{l}\text { (9) } \\
\rightarrow\end{array}$ & 6.0 & & \\
\hline
\end{tabular}

132 b. Sample a2,the loading and unloading step are (1) (9)

\begin{tabular}{|c|c|c|c|c|c|c|c|c|c|c|c|}
\hline$\sigma_{1} / \mathrm{MPa}$ & 7.0 & $\begin{array}{l}\text { (1) } \\
\rightarrow\end{array}$ & 10.63 & $\begin{array}{l}\text { (3) } \\
\rightarrow\end{array}$ & 14.25 & $\begin{array}{l}\text { (5) } \\
\rightarrow\end{array}$ & 17.88 & $\begin{array}{l}\text { (7) } \\
\rightarrow\end{array}$ & 21.5 & $\begin{array}{l}\text { (9) } \\
\rightarrow\end{array}$ & peak intensity \\
\hline$\sigma_{3} / \mathrm{MPa}$ & 7.0 & $\begin{array}{l}\text { (2) } \\
\rightarrow\end{array}$ & 4.0 & $\begin{array}{l}\text { (4) } \\
\rightarrow\end{array}$ & 7.0 & $\begin{array}{l}\text { (6) } \\
\rightarrow\end{array}$ & 4.0 & $\begin{array}{l}\text { (8) } \\
\rightarrow\end{array}$ & 7.0 & & \\
\hline
\end{tabular}

133 c. Sample a3, the loading and unloading step are (1) (10)

\begin{tabular}{|c|c|c|c|c|c|c|c|c|c|c|c|c|}
\hline$\sigma_{1} / \mathrm{MPa}$ & 7.0 & & 7.0 & $\begin{array}{l}(2) \\
\rightarrow\end{array}$ & 10.63 & $\begin{array}{l}\text { (4) } \\
\rightarrow\end{array}$ & 14.25 & $\begin{array}{l}\text { (6) } \\
\rightarrow\end{array}$ & 17.88 & $\begin{array}{l}\text { (8) } \\
\rightarrow\end{array}$ & 21.5 & $\begin{array}{l}\text { (10) } \\
\rightarrow\end{array}$ peak intensity \\
\hline$\sigma_{3} / \mathrm{MPa}$ & 7.0 & $\begin{array}{l}\text { (1) } \\
\rightarrow\end{array}$ & 8.0 & $\begin{array}{l}\text { (3) } \\
\rightarrow\end{array}$ & 4.0 & $\begin{array}{l}(5) \\
\rightarrow\end{array}$ & 8.0 & $\begin{array}{l}\text { (7) } \\
\rightarrow\end{array}$ & 4.0 & $\begin{array}{l}\text { (9) } \\
\rightarrow\end{array}$ & 8.0 & \\
\hline
\end{tabular}

d. Sample a4,the loading and unloading step are (1) (10)

\begin{tabular}{|c|c|c|c|c|c|c|c|c|c|c|c|c|c|}
\hline$\sigma_{1} / \mathrm{MPa}$ & 7.0 & & 7.0 & $\begin{array}{l}\text { (2) } \\
\rightarrow\end{array}$ & 10.63 & $\begin{array}{l}\text { (4) } \\
\rightarrow\end{array}$ & 14.25 & $\begin{array}{l}\text { (6) } \\
\rightarrow\end{array}$ & 17.88 & $\begin{array}{l}\text { (8) } \\
\rightarrow\end{array}$ & 21.5 & $\begin{array}{l}\text { (10) } \\
\rightarrow\end{array}$ & peak intensity \\
\hline$\sigma_{3} / \mathrm{MPa}$ & 7.0 & $\begin{array}{l}\text { (1) } \\
\rightarrow\end{array}$ & 9.0 & $\begin{array}{l}\text { (3) } \\
\rightarrow\end{array}$ & 4.0 & $\begin{array}{l}\text { (5) } \\
\rightarrow\end{array}$ & 9.0 & $\begin{array}{l}\text { (7) } \\
\rightarrow\end{array}$ & 4.0 & $\begin{array}{l}\text { (9) } \\
\rightarrow\end{array}$ & 9.0 & & \\
\hline
\end{tabular}

\section{Test results analysis}

\section{$136 \quad 3.1$ Stress sensitivity analysis}

137 Figure 3 shows the deviatoric stress-strain-permeability curve of each sample during loading and

138 unloading under different confining pressure conditions. 


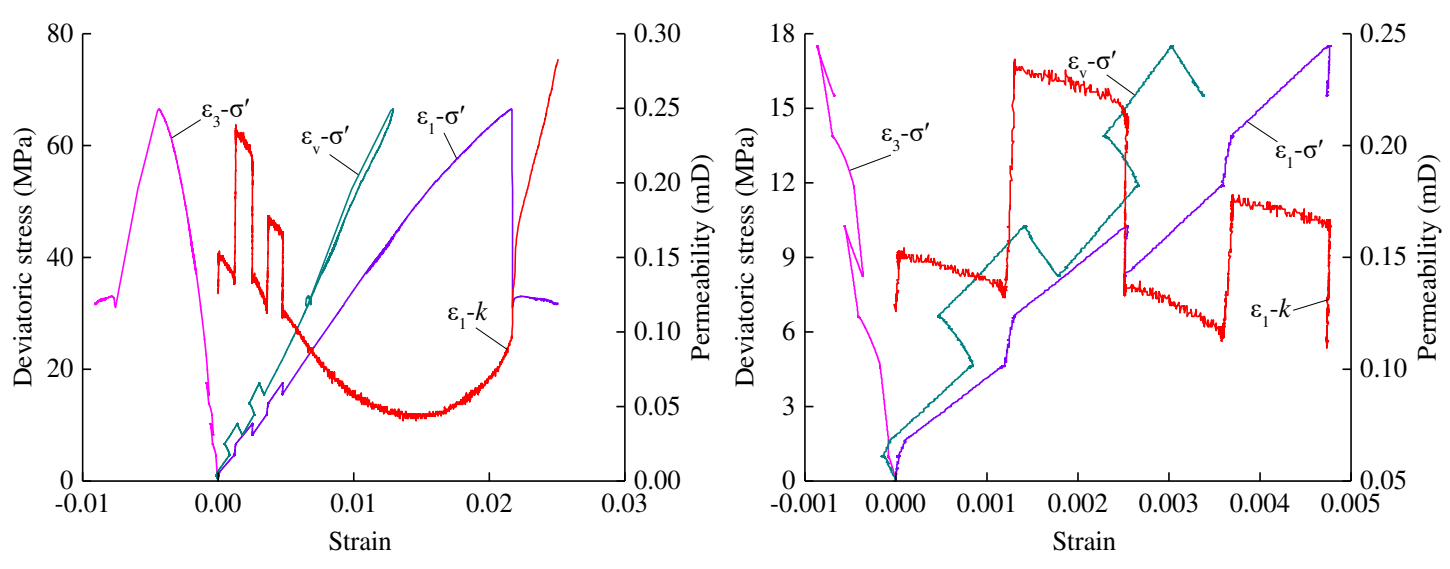

140

141

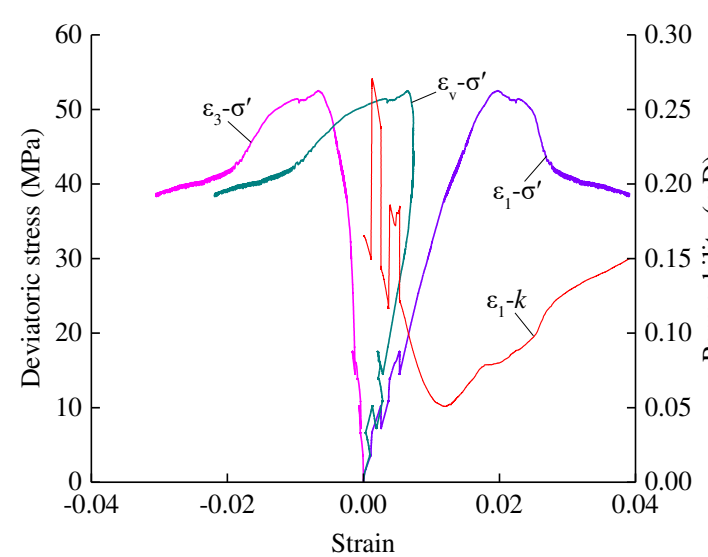

(a) sample $a_{1}$

142

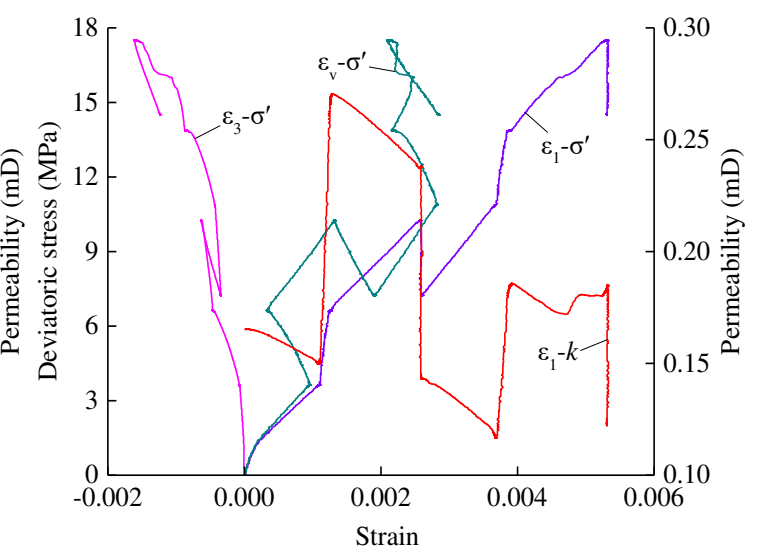

(b) sample $\mathrm{a}_{2}$
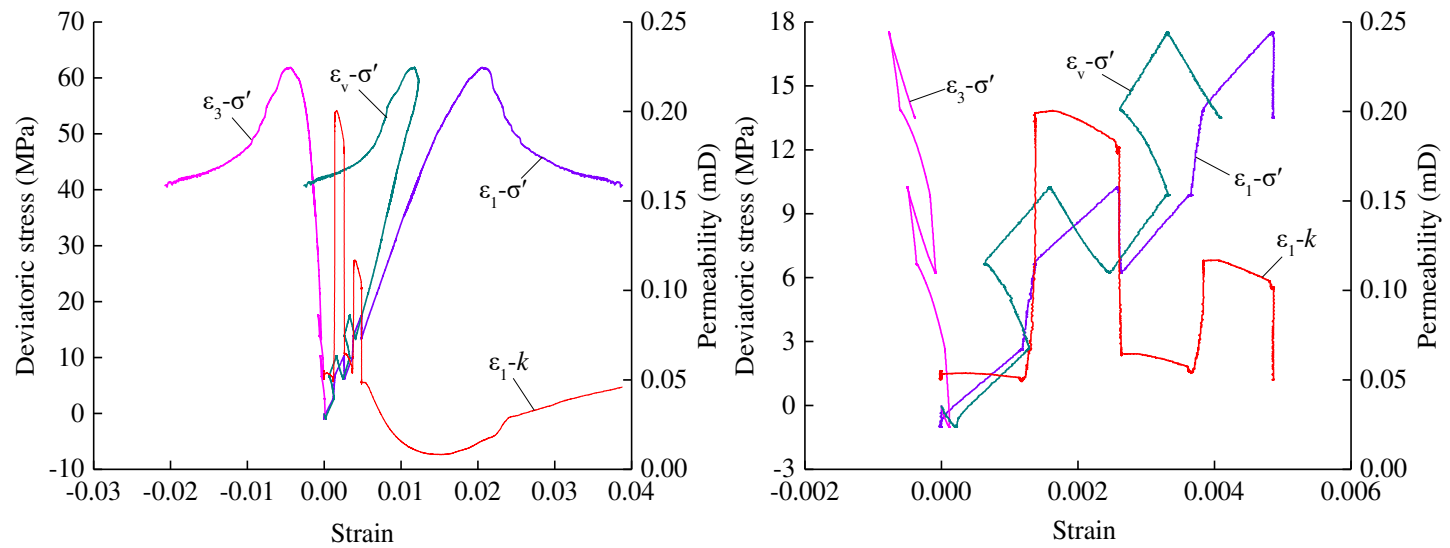

(c) sample a3 


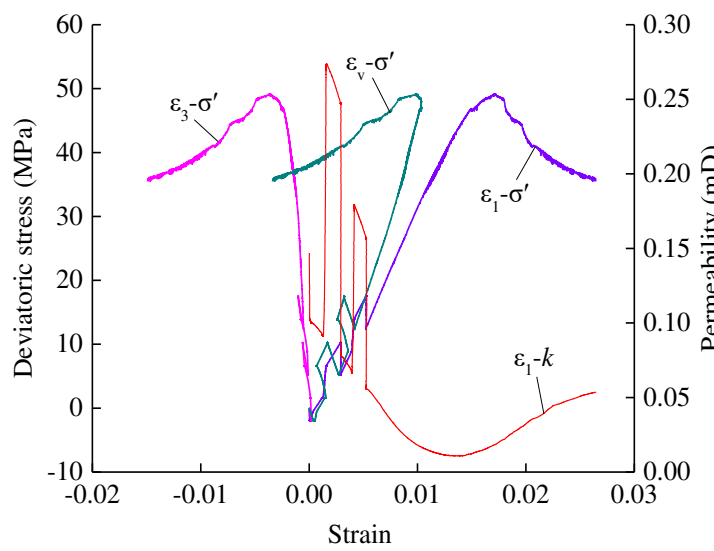

146

147

148 equations (2), (3) and (4).

Which, $\Delta \varepsilon_{1}=\varepsilon_{1 i+1}-\varepsilon_{1 i}, \Delta \varepsilon_{3}=\varepsilon_{3 i+1}-\varepsilon_{3 i}, \Delta \sigma=\left|\sigma_{1}-\sigma_{3}\right|$. are calculated, as shown in Table 1.

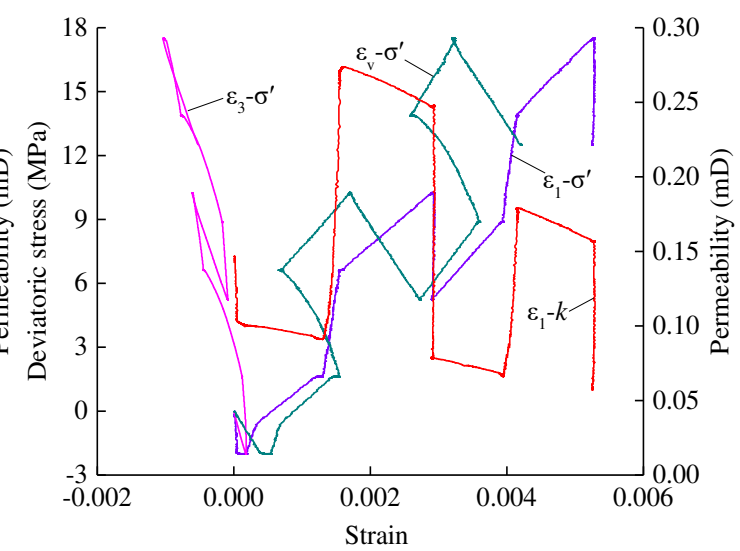

(d) sample $a_{4}$

Fig. 3 Deviatoric stress-strain-permeability curves of each sample during loading and unloading

It can be seen from Figure 3 that in the process of unloading confining pressure under constant axial stress, the specimen presents axial compression deformation and radial expansion deformation, and the sample permeability increases nonlinearly with the unloading of confining pressure. In the process of axial compression under constant confining pressure, the specimen continues to show compression deformation in axial direction and expansion deformation in radial direction. In the process of loading confining pressure under constant axial stress, the axial deformation of the sample is almost constant, and compression deformation in radial direction. The permeability of the sample decreases nonlinearly with the confining pressure. In order to more clearly analyze the sensitivity of axial stress and confining pressure to the deformation parameters of samples during the loading and unloading process, the axial strain change rate \& , radial strain change rate \& $\&$ and

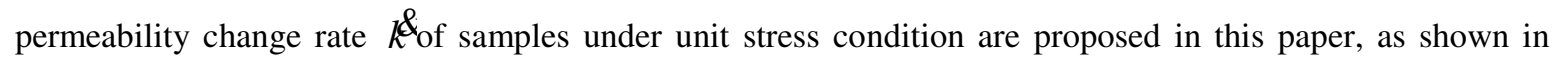

According to the test results in Figure 3, the axial strain change rate, radial strain change rate and permeability change rate of sample $a_{1}$ corresponding to different stress conditions during loading and unloading 


\begin{tabular}{ccccccccccc}
\hline$\sigma_{1} / \mathrm{MPa}$ & 7.0 & 7.0 & 10.63 & 10.63 & 14.25 & 14.25 & 17.88 & 17.88 & 21.5 & 21.5 \\
$\sigma_{3} / \mathrm{MPa}$ & 7.0 & 6.0 & 6.0 & 4.0 & 4.0 & 6.0 & 6.0 & 4.0 & 4.0 & 6.0 \\
\hline$\varepsilon_{1}^{\prime} / \%$ & - & 0.30 & 3.14 & 0.63 & 3.39 & -0.05 & 2.94 & 0.60 & 2.88 & -0.02 \\
$\varepsilon_{3}^{\prime} / \%$ & - & -0.84 & -0.25 & -1.19 & -0.41 & 1.00 & -0.28 & -1.15 & -0.47 & 0.93 \\
$\mathrm{k}^{\prime} / \%$ & - & 2.30 & -0.36 & 4.83 & -0.67 & -3.67 & -0.56 & 2.79 & -0.22 & -2.54 \\
\hline
\end{tabular}

Note: in the axial strain change rate, "+" represents axial compression and "-" represents axial expansion; in radial strain change rate, "+" represents radial compression and "-" represents radial expansion; in permeability change rate, "+" represents permeability increase and "-" represents permeability decrease.

It can be seen from Table 1 that the constant axial stress is $7.0 \mathrm{MPa}$, the confining pressure is unloaded from 7.0 MPa to 6.0 MPa, the corresponding sample axial strain change rate is $0.3 \%$, radial strain change rate is $0.84 \%$, and permeability change rate is $2.30 \%$. At this time, the permeability change rate is relatively large, while the axial strain change rate is relatively small; When the constant confining pressure is $6.0 \mathrm{MPa}$ and the axial stress is loaded from 7.0 MPa to $10.63 \mathrm{MPa}$, the sample axial strain change rate is $3.14 \%$, the radial strain change rate is $0.25 \%$, and the permeability change rate is $0.36 \%$. When the constant confining pressure is 6.0 $\mathrm{MPa}$ and the axial stress is loaded from $14.25 \mathrm{MPa}$ to $17.88 \mathrm{MPa}$, the sample axial strain change rate is $2.94 \%$, the radial strain change rate is $0.28 \%$, and the permeability change rate is $0.56 \%$. It can be seen that during the constant confining pressure of 6.0 MPa and the loading axial compression, the sample axial strain change rate is larger, and the radial strain change rate is smaller, and the axial strain change rate of the sample under high axial stress is smaller than the change rate value under low axial stress, while the radial strain change rate and permeability change rate of the sample are larger than the change rate of each parameter under low axial compression. When the constant confining pressure is 4.0 MPa and the axial stress is loaded from 10.63 MPa to 14.25 $\mathrm{MPa}$, the sample axial strain change rate is $3.39 \%$, the radial strain change rate is $0.41 \%$, and the permeability change rate is $0.67 \%$. When the constant confining pressure is $4.0 \mathrm{MPa}$ and the axial stress is loaded from 17.88 $\mathrm{MPa}$ to $21.5 \mathrm{MPa}$, the sample axial strain change rate is $2.88 \%$, the radial strain change rate is $0.47 \%$, and the permeability change rate is $0.22 \%$. It can be seen that the axial strain change rate of the sample is larger, the radial strain change rate of the sample is smaller when the axial stress is low, and the permeability change rate of the sample is smaller when the axial stress is high. Moreover, the axial strain change rate and the permeability change rate of the sample under high axial stress are lower than the value of change rate under low axial stress, while the radial strain change rate of the sample is opposite. When the constant axial stress is 10.63 $\mathrm{MPa}$ and the confining pressure is unloaded from 6.0 $\mathrm{MPa}$ to 4.0 $\mathrm{MPa}$, the sample axial strain change rate is $0.63 \%$, the radial strain change rate is $1.19 \%$, and the permeability change rate is $4.83 \%$. When the constant axial stress is $17.88 \mathrm{MPa}$ and the confining pressure is unloaded from $6.0 \mathrm{MPa}$ to $4.0 \mathrm{MPa}$, the sample axial strain change rate is $0.60 \%$, the radial strain change rate is $1.15 \%$, and the permeability change rate is $2.79 \%$. When the constant axial stress is $14.25 \mathrm{MPa}$ and the confining pressure is loaded from 4.0 MPa to 6.0 MPa, the sample axial strain change rate is $0.05 \%$, the radial strain change rate is $1.0 \%$, and the permeability change rate 
is $3.67 \%$. When the constant axial stress is $21.5 \mathrm{MPa}$ and the confining pressure is loaded from 4.0 MPa to 6.0

$202 \mathrm{MPa}$, the sample axial strain change rate is $0.02 \%$, the radial strain change rate is $0.93 \%$, and the permeability

203 change rate is $2.54 \%$. It can be seen that in the process of constant axial stress and loading-unloading confining

204 pressure, the permeability change rate of the sample is larger, the axial strain change rate of the sample is small,

205 and the change rate value of each parameter under high axial stress is smaller than that the change rate value of 206 each parameter under low axial stress.

It can be seen from the above analysis that constant axial stress and loading-unloading confining pressure

208 have a great influence on the permeability change rate of the sample, while less impact on the radial strain

209 change rate. Constant confining pressure and loading axial stress have a great influence on the axial strain 210 change rate of the specimen, but have little effect on the radial strain change rate.

211 From the test results in Figure 3(b), the axial strain change rate, radial strain change rate and permeability 212 change rate of sample $\mathrm{a}_{2}$ corresponding to different stress states during the loading and unloading process can be 213 calculated, as shown in Table 2.

Tab. 2 Test results of sample a2 alternate loading and unloading

\begin{tabular}{cccccccccc}
$\sigma_{1} / \mathrm{MPa}$ & 7.0 & 10.63 & 10.63 & 14.25 & 14.25 & 17.88 & 17.88 & 21.5 & 21.5 \\
$\sigma_{3} / \mathrm{MPa}$ & 7.0 & 7.0 & 4.0 & 4.0 & 7.0 & 7.0 & 4.0 & 4.0 & 7.0 \\
\hline$\varepsilon_{1}^{\prime} / \%$ & - & 3.01 & 0.52 & 3.62 & 0.07 & 3.01 & 0.66 & 3.95 & 0.03 \\
$\varepsilon_{3}^{\prime} / \%$ & - & -0.19 & -1.28 & -0.45 & 0.91 & -0.23 & -1.37 & -2.02 & 1.16 \\
$\mathrm{k}^{\prime} / \%$ & - & -0.42 & 3.83 & -0.75 & -3.11 & -0.72 & 2.20 & -0.04 & -2.00 \\
\hline
\end{tabular}

Note: in the axial strain change rate, "+" represents axial compression and "-" represents axial expansion; in radial strain change rate, "+" represents radial compression and "-" represents radial expansion; in permeability change rate, "+" represents permeability increase and "-" represents permeability decrease.

It can be seen from Table 2 that when the constant confining pressure is $7.0 \mathrm{MPa}$ and the axial stress is loaded from 7.0 MPa to $10.63 \mathrm{MPa}$, the axial strain change rate is $3.01 \%$, the radial strain rate is $0.19 \%$, and the permeability change rate is $0.42 \%$. When the confining pressure is $7.0 \mathrm{MPa}$ and the axial stress is loaded from 14.25 $\mathrm{MPa}$ to $17.88 \mathrm{MPa}$, the axial strain rate is $3.01 \%$, the radial strain rate is $0.23 \%$, and the permeability change rate is $0.72 \%$. It can be seen that with a constant confining pressure of $7.0 \mathrm{MPa}$ and loading axial stress, the change rate of axial strain is larger and that of radial strain is smaller. The radial strain change rate and permeability change rate of sample under high axial stress are higher than those under low axial stress, but the axial strain change rate is unchanged. When the confining pressure is $4.0 \mathrm{MPa}$ and the axial stress is loaded from 10.63 MPa to $14.25 \mathrm{MPa}$, the axial strain rate is $3.63 \%$, the radial strain rate is $0.45 \%$, and the permeability change rate is $0.75 \%$. When the confining pressure is $4.0 \mathrm{MPa}$ and the axial stress is from $17.88 \mathrm{MPa}$ to 21.5

$228 \mathrm{MPa}$, the axial strain rate is $3.95 \%$, the radial strain rate is $2.02 \%$, and the permeability change rate is $0.04 \%$. It 229 can be seen that the axial strain change rate is larger, and the higher the axial stress, the greater the axial strain 230 change rate. Due to the anisotropy of samples, the radial strain rate and permeability change rate are different. 
231 When the axial stress is $10.63 \mathrm{MPa}$ and the confining pressure is unloaded from 7.0 MPa to 4.0 MPa, the axial

232 strain change rate is $0.52 \%$, the radial strain change rate is $1.28 \%$, and the permeability change rate is $3.83 \%$.

233 When the axial stress is $14.25 \mathrm{MPa}$ and the confining pressure is loaded from 4.0 MPa to 7.0 MPa, the axial

234 strain change rate is $0.07 \%$, the radial strain change rate is $0.91 \%$, and the permeability change rate is $3.11 \%$.

235 When the axial stress is $17.88 \mathrm{MPa}$ and the confining pressure is unloaded from 7.0 MPa to 4.0 MPa, the axial 236 strain change rate is $0.66 \%$, the radial strain change rate is $1.37 \%$, and the permeability change rate is $2.20 \%$. It

237 can be seen that in the process of constant axial stress and loading-unloading confining pressure, the 238 permeability change rate is larger and the axial strain change rate is smaller, and the change rate of each 239 parameter under high axial stress is less than that under low axial stress.

240 According to the above analysis, under constant confining pressure and loading axial stress, the axial 241 strain change rate of the sample is larger than that of the radial strain change rate. In the process of constant axial 242 stress and loading-unloading confining pressure, the permeability change rate is larger, and the axial strain 243 change rate is smaller, and the change rate of each parameter under high axial stress is less than that under low 244 axial stress.

245 According to the test results in Figure 3(c), the axial strain change rate, radial strain change rate and permeability change rate of sample $\mathrm{a}_{3}$ under different stress states during loading and unloading can be calculated, as shown in Table 3.

Tab. 3 Test results of sample a3 alternate loading and unloading

\begin{tabular}{ccccccccccc}
\hline$\sigma_{1} / \mathrm{MPa}$ & 7.0 & 7.0 & 10.63 & 10.63 & 14.25 & 14.25 & 17.88 & 17.88 & 21.5 & 21.5 \\
$\sigma_{3} / \mathrm{MPa}$ & 7.0 & 8.0 & 8.0 & 4.0 & 4.0 & 8.0 & 8.0 & 4.0 & 4.0 & 8.0 \\
\hline$\varepsilon_{1}^{\prime} / \%$ & - & 0.19 & 3.16 & 0.53 & 3.30 & 0.15 & 2.81 & 0.49 & 2.74 & 0.02 \\
$\varepsilon_{3}^{\prime} / \%$ & - & 1.09 & -0.16 & -1.03 & -0.37 & 1.01 & -0.21 & -1.09 & -0.43 & 0.93 \\
$\mathrm{k}^{\prime} / \%$ & - & -0.41 & -0.02 & 3.29 & -0.13 & -2.78 & -0.31 & 1.42 & -0.21 & -1.34 \\
\hline
\end{tabular}

Note: in the axial strain change rate, "+" represents axial compression and "-" represents axial expansion; in radial strain change rate, "+" represents radial compression and "-" represents radial expansion; in permeability change rate, "+" represents permeability increase and "-" represents permeability decrease.

It can be seen from Table 3 that the constant axial stress is $7.0 \mathrm{MPa}$, the confining pressure is loaded from 7.0 MPa to $8.0 \mathrm{MPa}$, the sample axial strain change rate is $0.19 \%$, the radial strain change rate is $1.09 \%$, and the permeability change rate is $0.41 \%$. It can be seen that at the initial stage of constant axial stress and loading confining pressure, the radial strain change rate of the specimen is larger, and the axial strain change rate is smaller. When the constant axial stress is $14.25 \mathrm{MPa}$ and the confining pressure is loaded from 4.0 MPa to 8.0 $\mathrm{MPa}$, the sample axial strain change rate is $0.15 \%$, the radial strain change rate is $1.01 \%$, and the permeability

258 change rate is $2.78 \%$. When the constant axial stress is $21.5 \mathrm{MPa}$ and the confining pressure is loaded from 4.0

$259 \mathrm{MPa}$ to $8.0 \mathrm{MPa}$, the sample axial strain change rate is $0.02 \%$, the radial strain change rate is $0.93 \%$, and the 260 permeability change rate is $1.34 \%$. It can be seen that with constant axial stress and loaded confining pressure, 
the permeability change rate of the sample is larger, and the axial strain change rate is smaller, and the change rate of each parameter under high axial stress is smaller than that under low axial stress. When the constant axial stress is $10.63 \mathrm{MPa}$ and the confining pressure is unloaded from 8.0 MPa to 4.0 MPa, the sample axial strain change rate is $0.53 \%$, the radial strain change rate is $1.03 \%$, and the permeability change rate is $3.9 \%$. When the constant axial stress is $17.88 \mathrm{MPa}$ and the confining pressure is unloaded from 8.0MPa to 4.0 MPa, the sample axial strain change rate is $0.49 \%$, the radial strain change rate is $1.09 \%$, and the permeability change rate is $2.79 \%$. It can be seen that with constant axial stress and unloaded confining pressure, the permeability change rate of the sample is larger, and the axial strain change rate is smaller, and the change rate of each parameter under high axial stress is smaller than that under low axial stress. When the constant confining pressure is 8.0 $\mathrm{MPa}$ and the axial stress is loaded from $7.0 \mathrm{MPa}$ to $10.63 \mathrm{MPa}$, the sample axial strain change rate is $3.16 \%$, the radial strain change rate is $0.16 \%$, and the permeability change rate is $0.02 \%$. When the constant confining pressure is $8.0 \mathrm{MPa}$ and the axial stress is loaded from $14.25 \mathrm{MPa}$ to $17.88 \mathrm{MPa}$, the sample axial strain change rate is $2.81 \%$, the radial strain change rate is $0.21 \%$, and the permeability change rate is $0.31 \%$. When the constant confining pressure is $4.0 \mathrm{MPa}$ and the axial stress is loaded from 10.63 MPa to $14.25 \mathrm{MPa}$, the sample axial strain change rate is $3.30 \%$, the radial strain change rate is $0.37 \%$, and the permeability change rate is $0.13 \%$. When the constant confining pressure is 4.0 MPa and the axial stress is loaded from 17.88 MPa to 21.5 $\mathrm{MPa}$, the sample axial strain change rate is $2.71 \%$, the radial strain change rate is $0.43 \%$, and the permeability change rate is $0.21 \%$. It can be seen that under constant confining pressure and axial stress, the axial strain change rate is large, and the variation rate of radial strain and permeability is different due to the anisotropy of specimen.

According to the above analysis, under constant axial stress and loading confining pressure, the permeability change rate is larger and the axial strain change rate is smaller, and the change rate of each parameter under high axial stress is smaller than that under low axial stress. Under constant confining pressure and axial stress, the change rate of axial strain is large, and the change rate of radial strain and permeability is different due to the anisotropy of specimen.

According to the test results in Figure 3(d), the corresponding change rate of axial strain, radial strain and permeability of sample $\mathrm{a}_{4}$ under different stress states during loading and unloading can be calculated, as shown in Table 4.

Tab. 4 Test results of sample a4 alternate loading and unloading

\begin{tabular}{ccccccccccc}
\hline$\sigma_{1} / \mathrm{MPa}$ & 7.0 & 7.0 & 10.63 & 10.63 & 14.25 & 14.25 & 17.88 & 17.88 & 21.5 & 21.5 \\
$\sigma_{3} / \mathrm{MPa}$ & 7.0 & 9.0 & 9.0 & 4.0 & 4.0 & 9.0 & 9.0 & 4.0 & 4.0 & 9.0 \\
\hline$\varepsilon_{1}^{\prime} / \%$ & - & 0.48 & 3.31 & 0.52 & 3.69 & 0.04 & 2.73 & 0.54 & 3.00 & 0.00 \\
$\varepsilon_{3}^{\prime} / \%$ & - & 0.90 & -0.16 & -1.12 & -0.46 & 1.03 & -0.21 & -1.18 & -0.73 & 1.00 \\
$\mathrm{k}^{\prime} / \%$ & - & -2.24 & -0.30 & 3.55 & -0.60 & -3.34 & -0.34 & 2.17 & -0.54 & -1.98 \\
\hline
\end{tabular}


Note: in the axial strain change rate, "+" represents axial compression and "-" represents axial expansion; in radial strain change rate, "+" represents radial compression and "-" represents radial expansion; in permeability change rate, "+"

292 represents permeability increase and "-" represents permeability decrease.

293 It can be seen from Table 4 that the constant axial stress is $7.0 \mathrm{MPa}$, the confining pressure is loaded from

$2947.0 \mathrm{MPa}$ to $9.0 \mathrm{MPa}$, the axial strain change rate of the sample is $0.48 \%$, the radial strain change rate is $0.90 \%$,

295 and the permeability change rate is $2.24 \%$. When the axial stress is $14.25 \mathrm{MPa}$ and the confining pressure is

296 loaded from 4.0 MPa to 9.0 MPa, the axial strain change rate is $0.04 \%$, the radial strain change rate is $1.03 \%$,

297 and the permeability change rate is $3.34 \%$. When the axial stress is $21.5 \mathrm{MPa}$ and the confining pressure is

298 loaded from 4.0 MPa to 9.0 MPa, the axial strain change rate is $0.0 \%$, the radial strain change rate is $1.0 \%$, and

299 the permeability change rate is $1.98 \%$. It can be seen that under constant axial stress and loading confining

300 pressure, the permeability change rate is larger and the axial strain rate is smaller; When the constant confining

301 pressure is 9.0 MPa and the axial stress is loaded from 7.0 MPa to 10.63 MPa, the sample axial strain change

302 rate is $3.31 \%$, the radial strain change rate is $0.16 \%$, and the permeability change rate is $0.30 \%$. When the

303 constant confining pressure is 4.0 MPa and the axial stress is loaded from 10.63 MPa to 14.25 MPa, the sample

304 axial strain change rate is $3.69 \%$, the radial strain change rate is $0.46 \%$, and the permeability change rate is

$3050.60 \%$. When the constant confining pressure is $9.0 \mathrm{MPa}$ and the axial stress is loaded from 14.25 MPa to 17.88

$306 \mathrm{MPa}$, the sample axial strain change rate is $2.73 \%$, the radial strain change rate is $0.21 \%$, and the permeability

307 change rate is $0.34 \%$. When the constant confining pressure is $4.0 \mathrm{MPa}$ and the axial stress is loaded from 17.88

$308 \mathrm{MPa}$ to $21.5 \mathrm{MPa}$, the sample axial strain change rate is $3.0 \%$, the radial strain change rate is $0.73 \%$, and the

309 permeability change rate is $0.54 \%$. It can be seen that with constant confining pressure and loaded axial stress,

310 the sample axial strain change rate is larger, and the radial strain change rate is smaller; When the constant axial

311 stress is $10.63 \mathrm{MPa}$ and the confining pressure is unloaded from 9.0 MPa to 4.0 MPa, the sample axial strain

312 change rate is $0.52 \%$, the radial strain change rate is $1.12 \%$, and the permeability change rate is $3.55 \%$. When

313 the constant axial stress is $17.88 \mathrm{MPa}$ and the confining pressure is unloaded from 9.0 $\mathrm{MPa}$ to 4.0 $\mathrm{MPa}$, the

314 sample axial strain change rate is $0.54 \%$, the radial strain change rate is $1.18 \%$, and the permeability change rate

315 is $2.17 \%$. It can be seen that, with constant axial stress and unloaded confining pressure, the permeability

316 change rate of sample is larger, and the axial strain change rate is smaller.

317 The above analysis shows that with constant axial stress and loading-unloading confining pressure, the

318 permeability change rate of the sample is larger, and the axial strain change rate is smaller. With constant

319 confining pressure and load axial stress, the sample axial strain change rate is larger, and the radial strain change

320 rate is smaller.

\subsection{Analysis of coal gas seepage by loading-unloading}

322 According to the test results in Figure 3, the deviatoric stress-permeability curve of each sample under different confining pressures are plotted, as shown in Figure 4. 


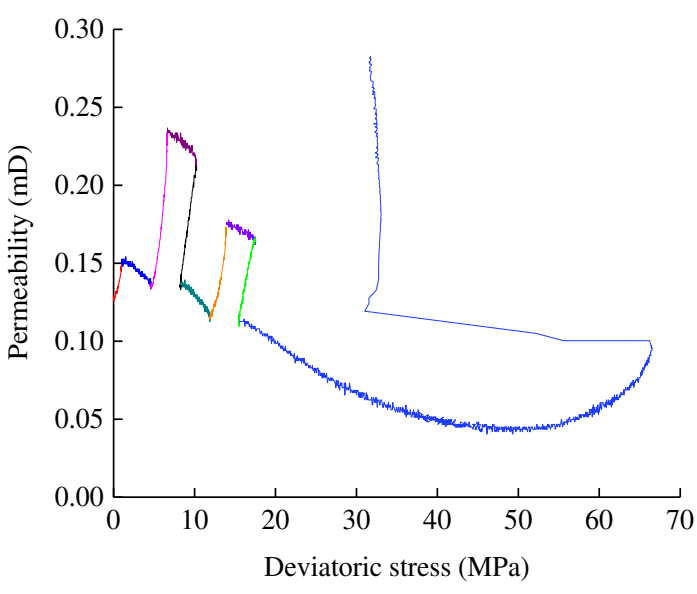

(a) $\sigma_{3}=6 \mathrm{MPa}$

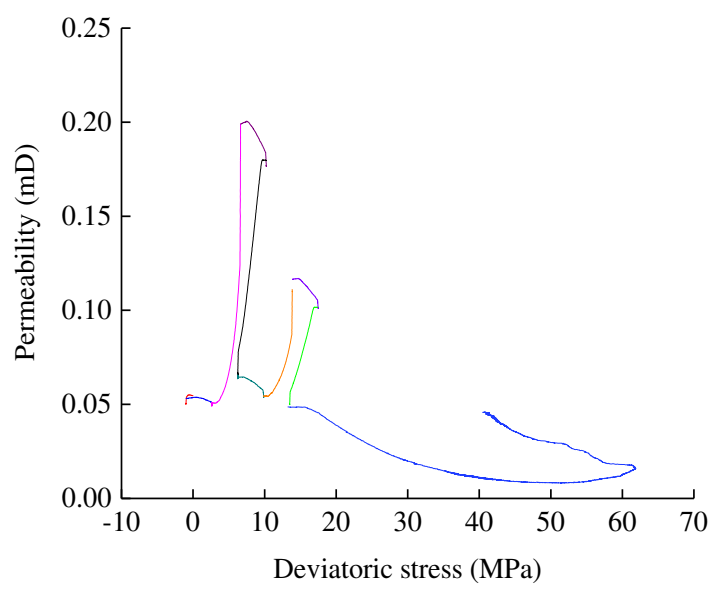

(c) $\sigma_{3}=8 \mathrm{MPa}$

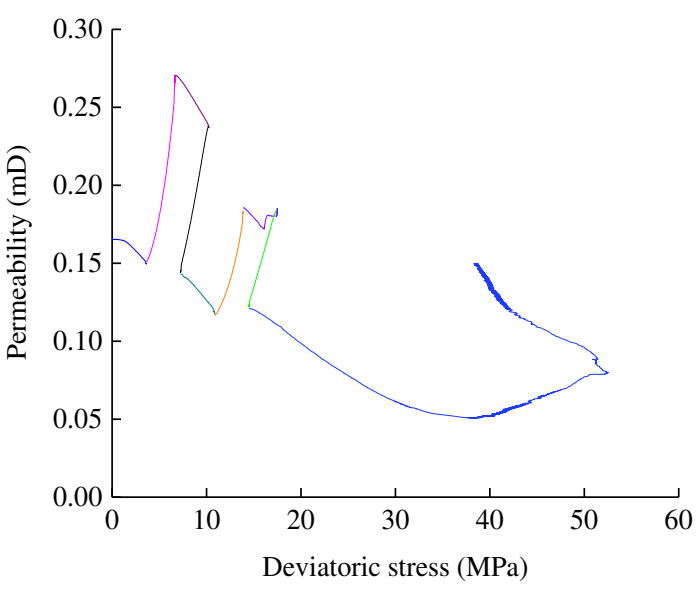

(b) $\sigma_{3}=7 \mathrm{MPa}$

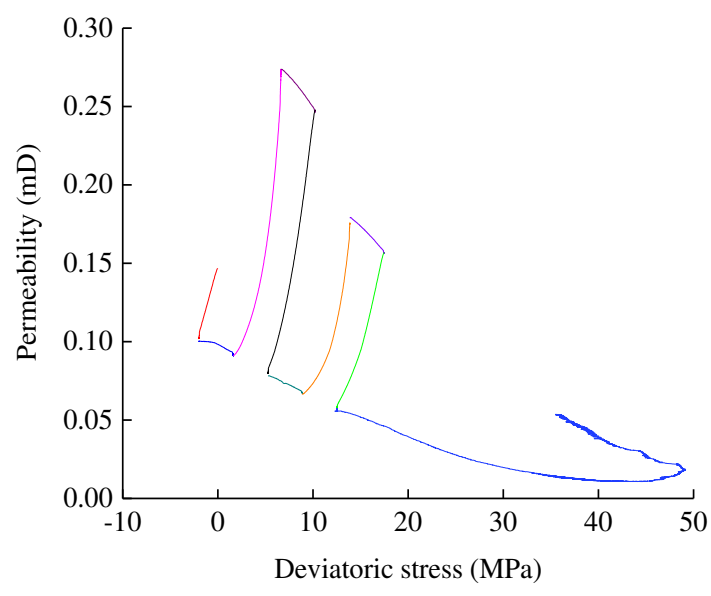

(d) $\sigma_{3}=9 \mathrm{MPa}$

Fig. 4 Permeability-deviatoric stress curve of samples during alternate loading and unloading under different confining pressure

331 of the sample gradually increases under the condition of constant axial stress and unloading confining pressure,

332 and the permeability of the sample increases nonlinearly with the increase of the deviatoric stress, this is

333 because the axial stress is constant, and with the unloading of the confining pressure, the internal micropores

334 and cracks in the sample slowly open, and the gas passing capacity is enhanced. Under the condition of constant

335 confining pressure and axial stress, the deviatoric stress of the sample increases gradually, and the permeability

336 of the sample decreases nonlinearly with the increase of the deviator stress. This is because the confining 337 pressure is constant, the micropores and cracks inside the sample are slowly closed with the loading of the axial 338 stress, the gas passing capacity is weakened, and the permeability of the sample is reduced. Under the condition 339 of constant axial stress and loading confining pressure, the deviator stress of the sample further decreases, and 340 the permeability of the sample decreases nonlinearly with the decrease of the deviator stress. This is because of 341 the constant axial stress, with the loading of the confining pressure, the internal micropores and fissures of the 342 sample are further compacted and closed, the gas permeability channel is blocked, and the gas passing capacity 
343 is weakened, resulting in the decrease of the sample permeability. Subsequently, during the process of constant

344 confining pressure and displacement controlled axial stress, the permeability of the sample decreases

345 nonlinearly with the increase of the deviator stress. When the stress is loaded to the yield stage, cracks appear in

346 the sample, and the permeability of the sample increases slowly. When the sample reaches the ultimate

347 load-bearing capacity, the sample will be destabilized and destroyed, forming a through crack, and the

348 permeability of the sample will increase rapidly, but the permeability of the sample has not reached the initial

349 permeability of the sample under the action of the confining pressure.

350 The increase and decrease range of the sample permeability under the action of alternate loading and

351 unloading under different confining pressure conditions is shown in Table 5. In the table, "+" means increase,

352 and "-" means decrease. It can be seen that under the condition of constant axial stress, the increase range of

353 sample permeability gradually increases with the increase of unloading confining pressure range, and the

354 increase range of sample permeability after unloading confining pressure at $17.88 \mathrm{MPa}$ is lower than that after

355 unloading confining pressure at 10.63 MPa. Similarly, under the condition of constant axial stress, with the

356 increase of the loading confining pressure range, the decrease range of sample permeability also gradually

357 increases, and the decrease range of sample permeability after loading confining pressure at $21.5 \mathrm{MPa}$ is lower

358 than that after loading confining pressure of 14.25 MPa. Compared with that under the unloading confining

359 pressure, the increase range of permeability is higher than the decrease range of the sample permeability under

360 the increase of confining pressure.

Tab. 5 Increase and decrease range of permeability under loading and unloading

\begin{tabular}{|c|c|c|c|c|c|c|c|}
\hline \multicolumn{2}{|c|}{$\sigma_{1} / \mathrm{MPa}$} & $10.63 \mathrm{MPa}$ & $17.88 \mathrm{MPa}$ & \multicolumn{2}{|c|}{$\sigma_{1} / \mathrm{MPa}$} & 14.25 & 21.5 \\
\hline \multirow{4}{*}{$\sigma_{3} / \mathrm{MPa}$} & $6 \rightarrow 4$ & $+70.54 \%$ & $+48.31 \%$ & \multirow{4}{*}{$\sigma_{3} / \mathrm{MPa}$} & $4 \rightarrow 6$ & $-35.03 \%$ & $-31.11 \%$ \\
\hline & $7 \rightarrow 4$ & $+76.65 \%$ & $+56.07 \%$ & & $4 \rightarrow 7$ & $-39.34 \%$ & $-32.99 \%$ \\
\hline & $8 \rightarrow 4$ & $+265.04 \%$ & $+104.29 \%$ & & $4 \rightarrow 8$ & $-62.90 \%$ & $-51.74 \%$ \\
\hline & $9 \rightarrow 4$ & $+194.51 \%$ & $+161.22 \%$ & & $4 \rightarrow 9$ & $-67.65 \%$ & $-63.35 \%$ \\
\hline
\end{tabular}

Table 6 and Table 7 show the decrease range of permeability under axial the condition of loading axial stress, and the "-" in the table indicates decrease. It can be seen from Table 6 that when the confining pressure is constant and the axial stress is loaded to $17.88 \mathrm{MPa}$, the permeability reduction range of the sample is greater than that of the axial stress loading to $10.63 \mathrm{MPa}$, and with the increase of confining pressure, the decrease range of the sample permeability increases during the loading process. It can be seen from Table 7 that when the constant confining pressure is $4 \mathrm{MPa}$ and the axial stress is loaded from 10.63 $\mathrm{MPa}$ to $14.25 \mathrm{MPa}$, with the

368 increase of the loading and unloading range of the confining pressure, the decrease range of the permeability of 369 the sample shows an increasing trend with the increase of the loading and unloading range of the confining 370 pressure. 
Tab. 6 Increase and decrease range of permeability under loading and unloading

\begin{tabular}{cccccc}
\hline & $\sigma_{3} / \mathrm{MPa}$ & $6 \mathrm{MPa}$ & $7 \mathrm{MPa}$ & $8 \mathrm{MPa}$ & $9 \mathrm{MPa}$ \\
\hline \multirow{2}{*}{$\sigma_{1} / \mathrm{MPa}$} & $7 \rightarrow 10.63$ & $-8.67 \%$ & $-9.24 \%$ & $-1.32 \%$ & $-10.54 \%$ \\
& $14.25 \rightarrow 17.88$ & $-15.03 \%$ & $-18.25 \%$ & $-17.06 \%$ & $-15.58 \%$ \\
\hline
\end{tabular}

Tab. 7 Increase and decrease range of permeability of sample under loading and unloading

\begin{tabular}{cccccc}
\hline & \multicolumn{1}{c}{$\sigma_{3} / \mathrm{MPa}$} & $4(6 \mathrm{MPa})$ & $4(7 \mathrm{MPa})$ & $4(8 \mathrm{MPa})$ & $4(9 \mathrm{MPa})$ \\
\hline \multirow{2}{*}{$\sigma_{1} / \mathrm{MPa}$} & $10.63 \rightarrow 14.25$ & $-10.31 \%$ & $-10.29 \%$ & $-2.64 \%$ & $-8.13 \%$ \\
& $17.88 \rightarrow 21.5$ & $-4.68 \%$ & $-0.75 \%$ & $-6.94 \%$ & $-11.12 \%$ \\
\hline
\end{tabular}

In the process of loading axial stress and loading confining pressure, the permeability of the sample decreases nonlinearly with the increase of deviatoric stress. During the process of unloading confining pressure, the permeability of the sample increases nonlinearly with the decrease of deviatoric stress.

The relationship between the permeability and the principal stress difference of the fitting sample is in accordance with the negative exponential function, see equation (5):

$$
k=a \cdot \exp \left(-b \sigma^{\prime}\right)+c
$$

Among them, a, b, c are the fitting parameters, which are limited in space. In this paper, the relationship

383 between permeability and principal stress difference of sample $\mathrm{a}_{1}$ is analyzed, and the fitting curve is shown in

384 Figure 5.

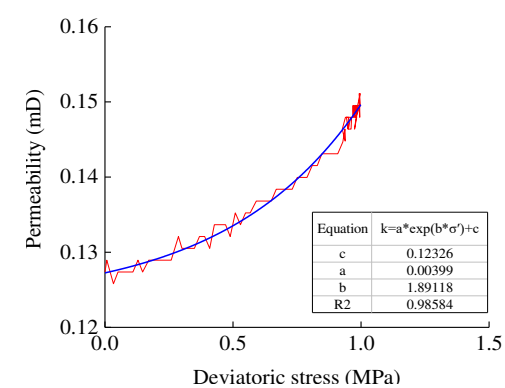

(a) $\sigma_{3}: 7.0 \rightarrow 6.0$

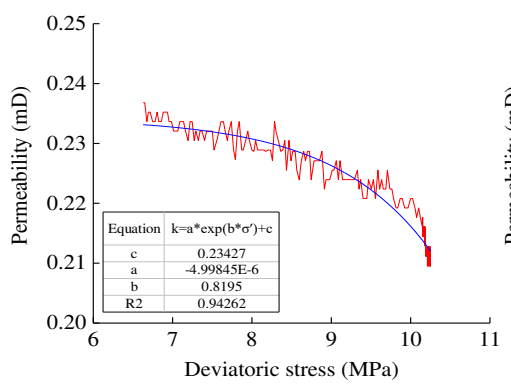

(d) $\sigma_{1}: 10.63 \rightarrow 14.25$

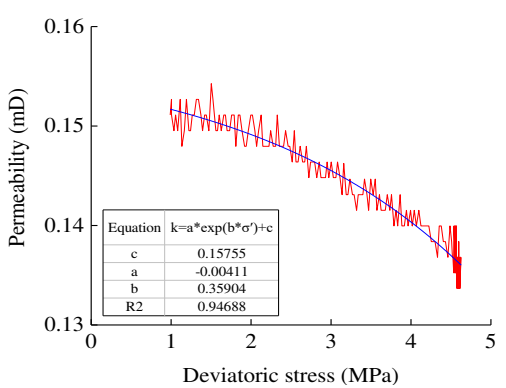

(b) $\sigma_{1}: 7.0 \rightarrow 10.63$

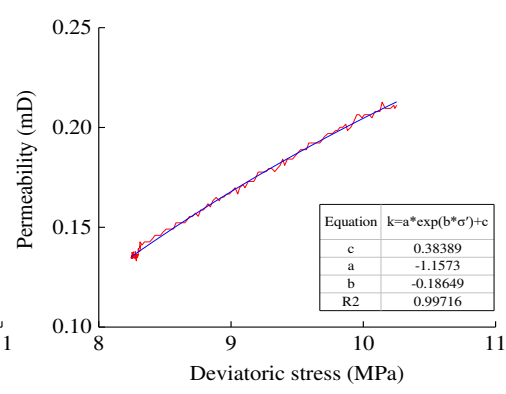

(e) $\sigma_{3}: 4.6 \rightarrow 6.0$

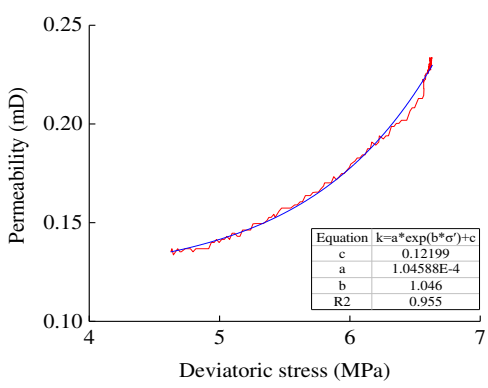

(c) $\sigma_{3}: 6.0 \rightarrow 4.0$

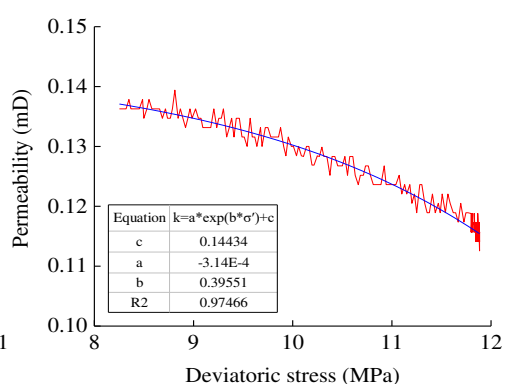

(f) $\sigma_{1}: 14.25 \rightarrow 17.88$ 


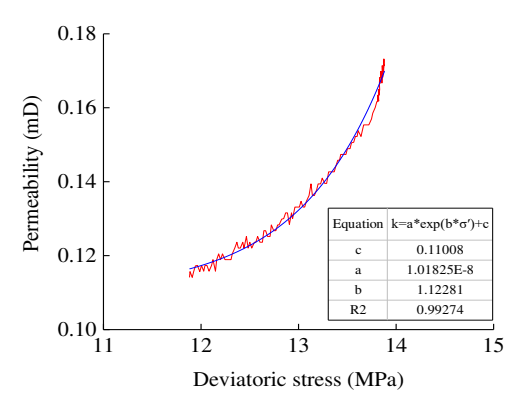

$(\mathrm{g}) \sigma_{3}: 6.0 \rightarrow 4.0$

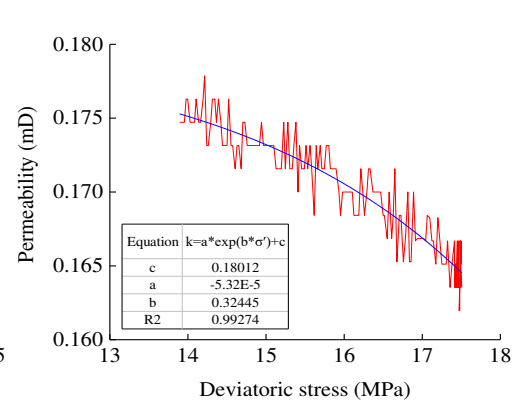

(h) $\sigma_{1}: 17.88 \rightarrow 21.5$

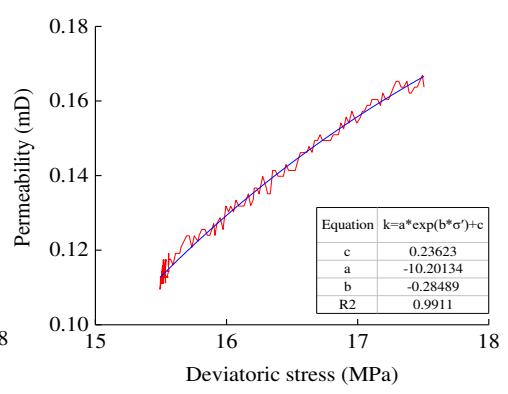

(i) $\sigma_{3}: 4.6 \rightarrow 6.0$

Fig. 5 Relationship curve between permeability of sample a1 and deviatoric stress during loading-unloading

\section{Conclusion}

In this paper, the cyclic loading and unloading confining pressure tests of raw coal samples were carried out by using the "Triaxial seepage test device of thermal fluid solid of coal and rock" developed by Chongqing University, the conclusions are as follows:

1) The axial strain change rate $\varepsilon_{1}^{\prime}$, the radial strain change rate $\varepsilon_{3}^{\prime}$ and the permeability change rate $k^{\prime}$ under unit stress state are used to represent the sensitivity of axial stress and confining pressure to deformation and permeability characteristics of samples under unit stress state.

2) At the initial stage of unloading the confining pressure, the confining pressure has a greater influence on the permeability of the sample. At the initial stage of loading confining pressure, the confining pressure has a greater influence on the radial strain of the specimen. During the subsequent loading and unloading process, the confining pressure of loading and unloading has a greater influence on the permeability of the sample, and a smaller influence on the axial strain. The loading axial stress has a greater influence on the axial strain of the sample, and a smaller influence on the permeability of the sample.

3) When the axial stress is constant, the increase range of sample permeability increases with the increase of unloading confining pressure range, and the decreasing range of sample permeability increases with the increase of loading confining pressure range, and the increase range of sample permeability under unloading confining pressure is higher than that under increasing confining pressure.

4) In the process of loading axial stress and loading confining pressure, the permeability of samples decreases nonlinearly with the increase of principal stress difference, while the permeability of samples increases nonlinearly with the decrease of principal stress difference in the process of unloading confining pressure.

\section{Data Availability}

414 The data used to support the study is available within the article.

\section{Conflicts of Interest}

416 The authors declare that they have no conflicts of interest. 
Y.Y. conceived the original idea for this study. B. Z. and Y.Y. prepared all samples for analysis. B.Z. collected and analysed the data. Y.Y. wrote the manuscript. All the authors gave their final approval for publication.

\section{Acknowledgements}

This research was finally Funded by the Research Fund of State and Local Joint Engineering Laboratory for Gas Drainage \& Ground Control of Deep Mines (Henan Polytechnic University SJF202004), Doctoral Research Fund (Z301B20536), and the Housing and Urban-rural Development Project of Jiangsu Province (Z413B19341).

\section{References}

Duan MK, Jiang CB, Yu H, Lu TY, Niu BW, Sun DL. Experimental research on energy dissipation and seepage properties of coal under loading-unloading conditions at different stress levels. Rock and Soil Mechanics. 2018, 39(4): 1346-1354.

Jia HY, Wang K, Wang YB, Sun XK. Permeability characteristics of gas-bearing coal specimens under cyclic loading-unloading of confining pressure. Journal of China Coal Society. 2020, 45(5): $1710-1718$.

Ju Y, Zhang QG, Zheng JT, Wang JG, Chang C, Gao F. Experimental study on CH4 permeability and its dependence on interior fracture networks of fractured coal under different excavation stress paths. Fuel. 2017, 202: 483-493.

Li XQ, Yin GZ, Cai B. Experimental study on deformation and seepage properties of outburst coal samples under cyclic loading. Chinese Journal of Rock Mechanics and Engineering, 2010, 29(S2): 3498-3504.

Liu YQ. Experimental analysis of coal permeability evolution under cyclic loading. Journal of China Coal Society. 2019 44(8): 2579-2588.

Li BB, Li JH, Yang K, Ren CH, Xu J, Gao Z. Coal permeability model and evolution law considering water influence. Journal of China Coal Society. 2019, 41(11): 3396-3403.

Li Y, Tang D, Xu H, Meng YJ, Li JQ. Experimental research on coal permeability: The roles of effective stress and gas slippage. Journal of Natural Gas Science and Engineering, 2014, 21: 481-488.

Wang G, Li WX, Du WZ, Wang HY, Wang PF, Sun WB. Experimental study of coal deformation and permeability characteristics of gas under variable axial compressive loadings. Rock and Soil Mechanics. 2016, 37(S1): 175-182.

$\mathrm{Xu}$ J, Li BB, Cao J, Ye GB. Experimental study of deformation and seepage characteristics of coal under cyclic loading. Chinese Journal of Rock Mechanics and Engineering, 2014, 33(2): 225-234.

Xiao XC, Pan YS, Lü XF, Luo H, Li ZH. Experimental research on gas flow law of containing water coal specimens in deformation and fracture process. Journal of China Coal Society. 2012, 37(Z1): 115-119. 
Xu J, Li BB, Zhou T, Liu D, Chen LC, Cao J. Experimental study of coal deformation and permeability characteristics under loading-unloading conditions. Journal of China Coal Society. 2012, 37(9): 1493-1498.

Xin CP, Wang K, Du F, Zhang X, Wang GD, Liu YL. Mechanical properties and permeability evolution of gas-bearing coal under phased variable speed loading and unloading. Arabian Journal of Geosciences, 2018, 11(23): 747.

Yuan X, Zhang JW. Deformation and permeability characteristic of outburst coal under step unloading conditions. Journal of China Coal Society. 2017, 42(6): 1451-1457.

Yin GZ, Liu YB, Li MH, Deng BZ, Liu C, Lu J. Influence of true triaxial loading-unloading stress paths on mechanical property and permeability of coal. Journal of China Coal Society. 2018, 43(1): 131-136.

Ye ZW, Zhang L, Hao DY, Wang C. Experimental study on the response characteristics of coal permeability to pore pressure under loading and unloading conditions. Journal of Geophysics \& Engineering. 2017, 14: 1020-1031.

Zhang XM, Zhang DM, LEO CJ, et al. Damage evolution and post-peak gas permeability of raw coal under loading and unloading conditions. Transport in Porous Media, 2017, 117(3): 465-480.

Zhao HB, Wang T, Zhang H, Li JS, Li JY. Experimental study of the effect of penetration gangue on coal permeability. Journal of China University of Mining \& Technology. 2019, 48(1): 29-35.

Zhu J, Wang Q, Tang J, Chen WY, Jiang YD, Tang D, Lan TX. Evolution characteristics of strain and permeability of coal samples under loading and unloading conditions. Journal of China Coal Society. 2020. doi:10.13225/j.cnki.jccs.dy20.0280.

Zhao HG, Zhang DM, Liu C, Deng BZ, Bian G, Li WP. Mechanical characteristics and permeability evolution rule of coal under loading-unloading conditions. Chinese Journal of Engineering. 2016, 38(12): 1674-1680.

Zou JP, Chen WZ, Yang DS, Yu HD, Yuan JQ. The impact of effective stress and gas slippage on coal permeability under cyclic loading. Journal of Natural Gas Science and Engineering, 2016, 31: 236-248. 


\section{Figures}

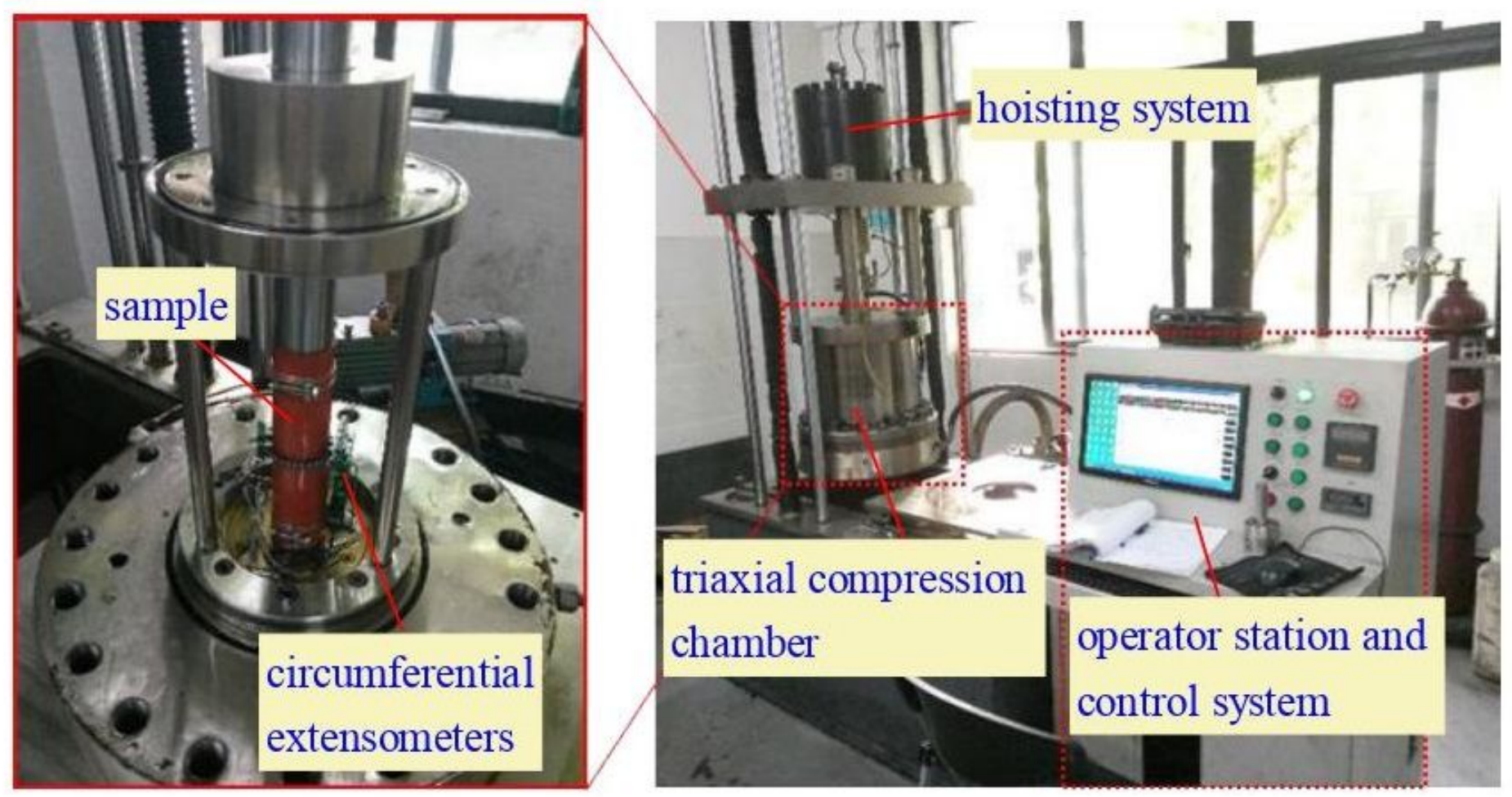

Figure 1

Tri-axial stress thermal-hydrological-mechanical Coal Gas Permeameter 


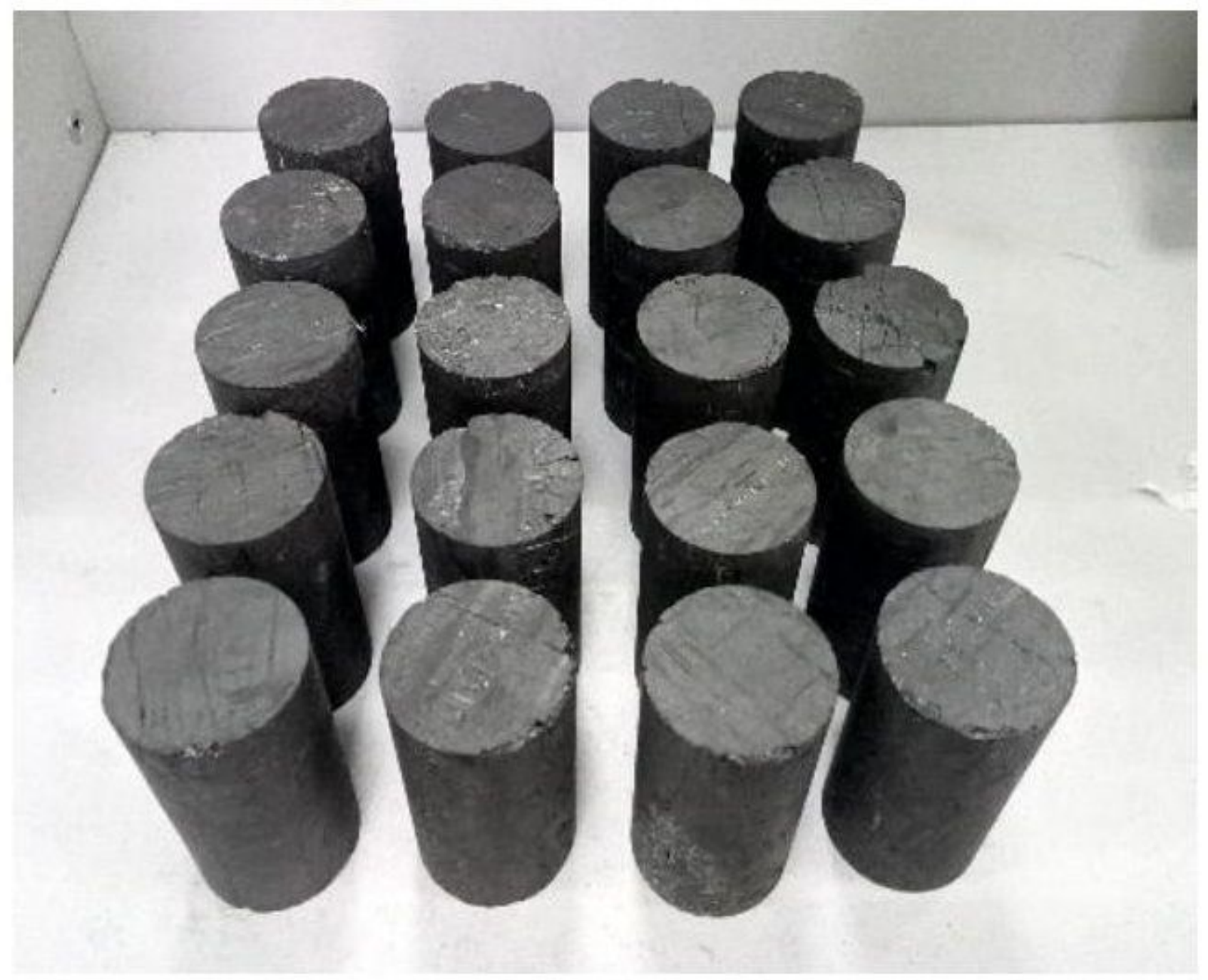

Figure 2

Raw coal sample 

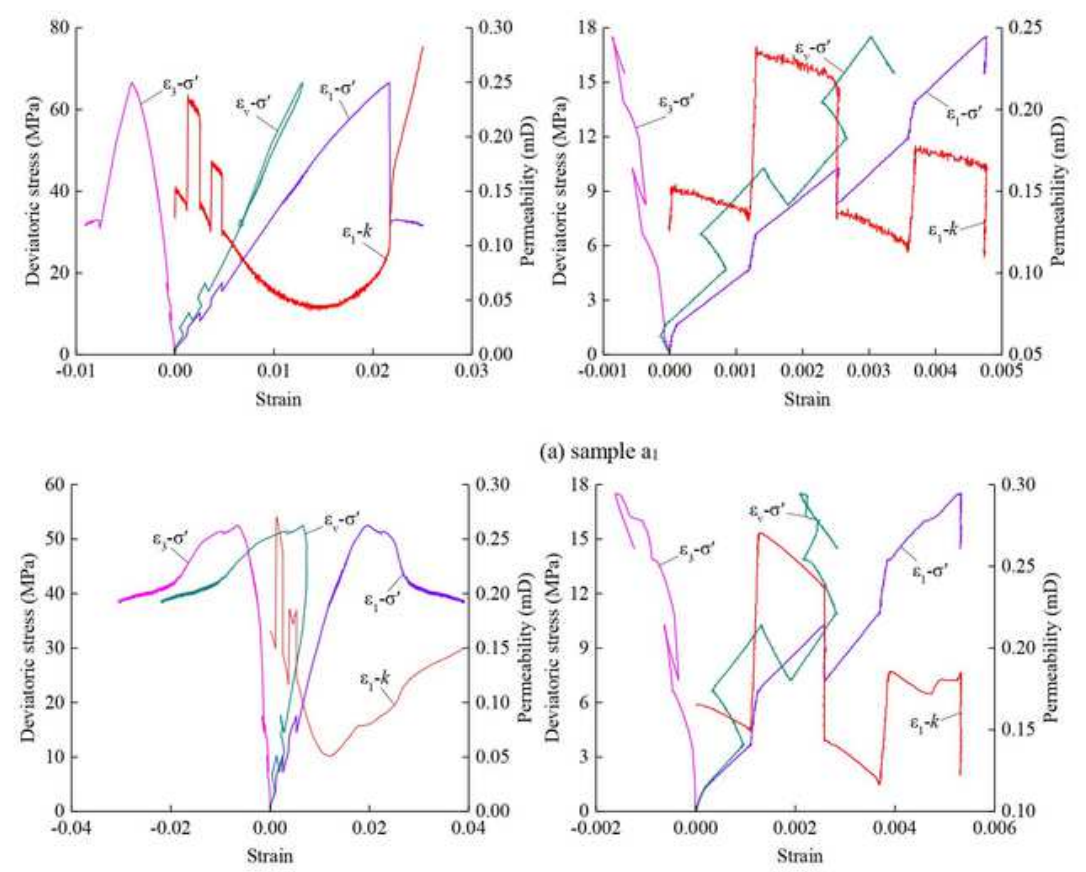

(a) sample at

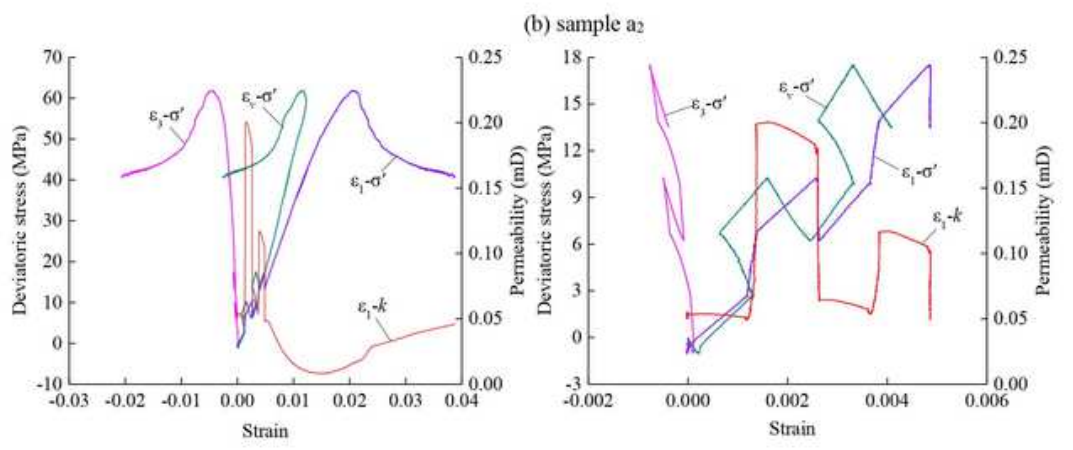

(c) sample a3

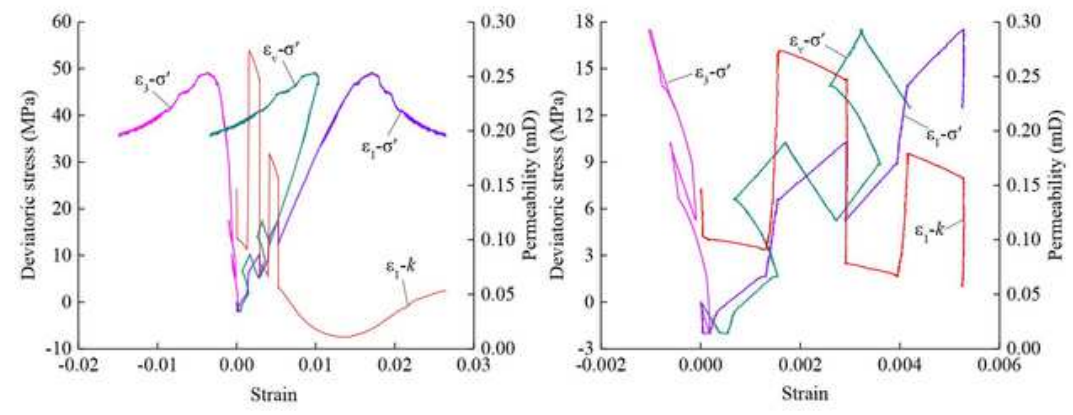

(d) sample a4

\section{Figure 3}

Deviatoric stress-strain-permeability curves of each sample during loading and unloading 


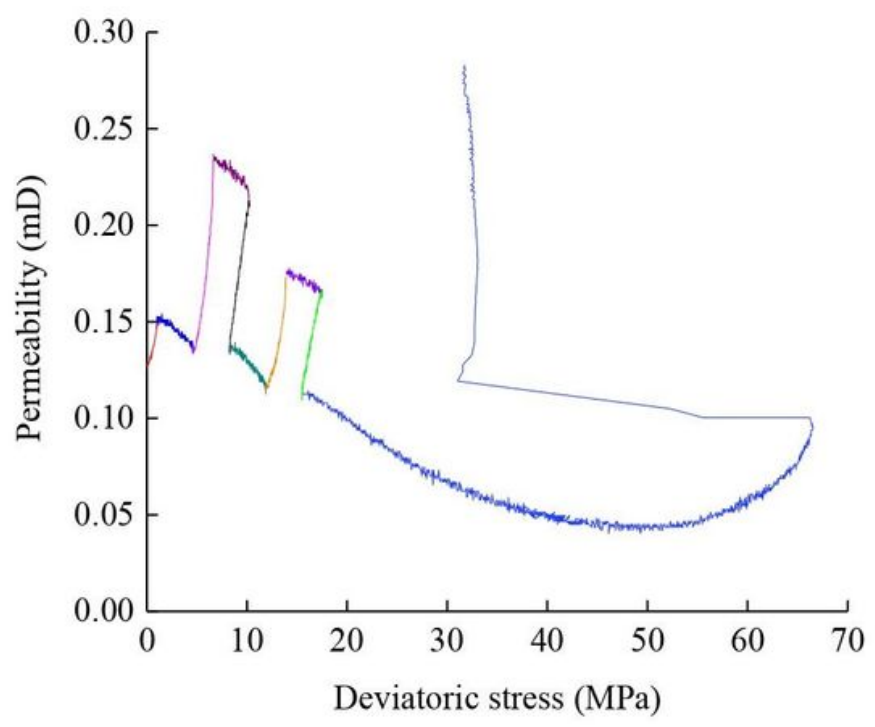

(a) $\sigma_{3}=6 \mathrm{MPa}$

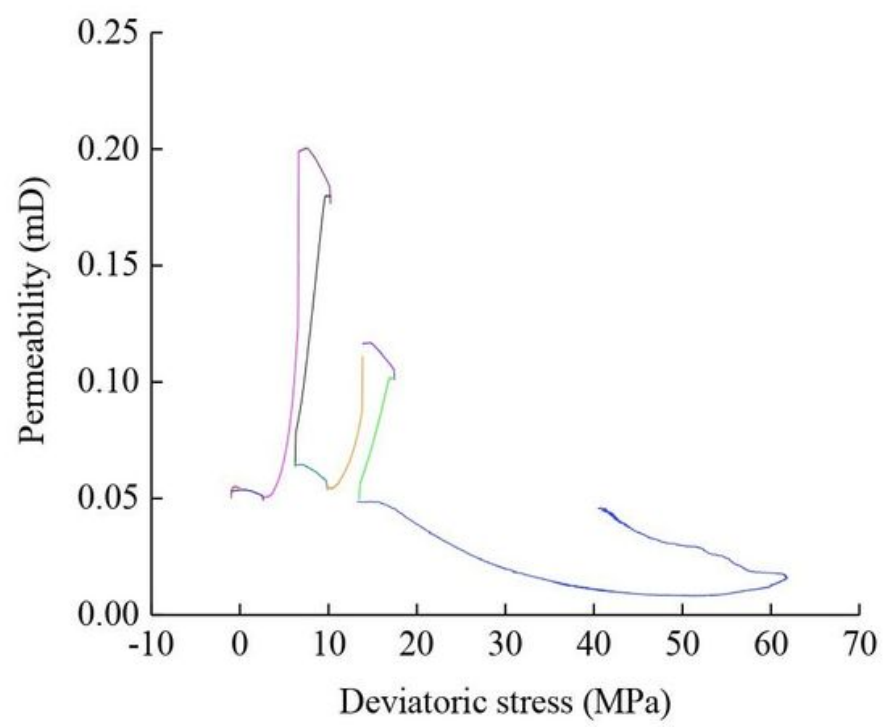

(c) $\sigma_{3}=8 \mathrm{MPa}$

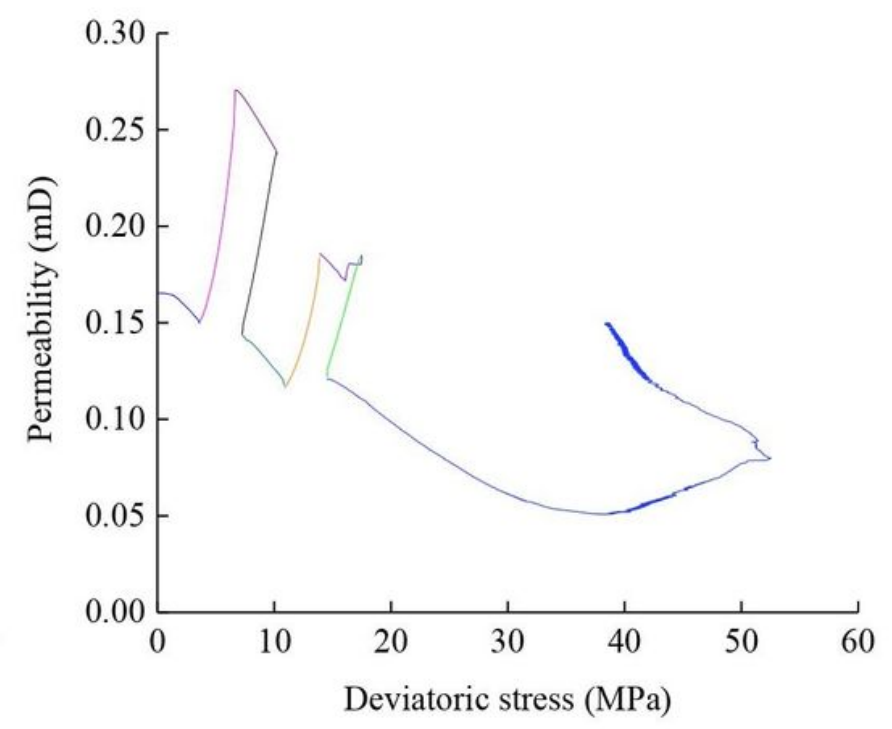

(b) $\sigma_{3}=7 \mathrm{MPa}$

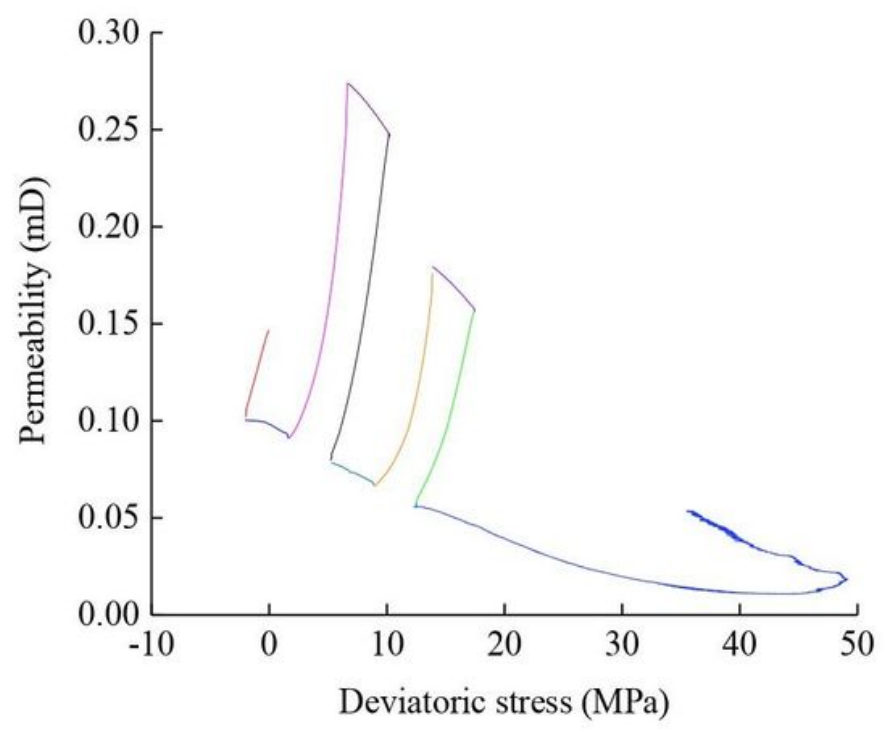

(d) $\sigma_{3}=9 \mathrm{MPa}$

\section{Figure 4}

Permeability-deviatoric stress curve of samples during alternate loading and unloading under different confining pressure 


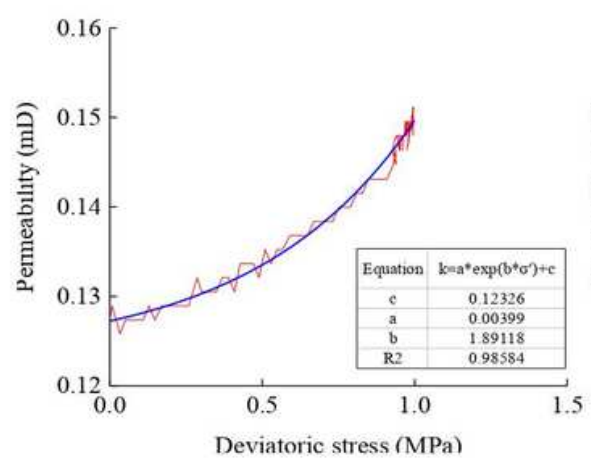

(a) $\sigma_{3}: 7.0 \rightarrow 6.0$

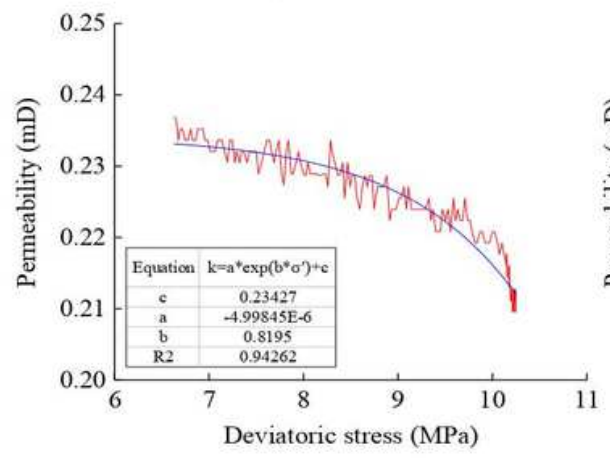

(d) $\sigma_{1}: 10.63 \rightarrow 14.25$

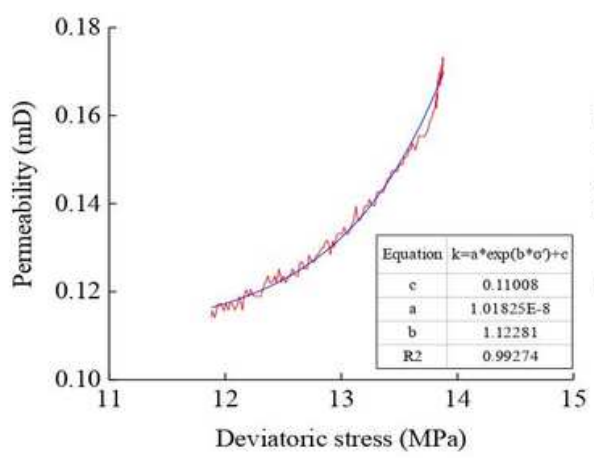

(g) $\sigma_{3}: 6.0 \rightarrow 4.0$

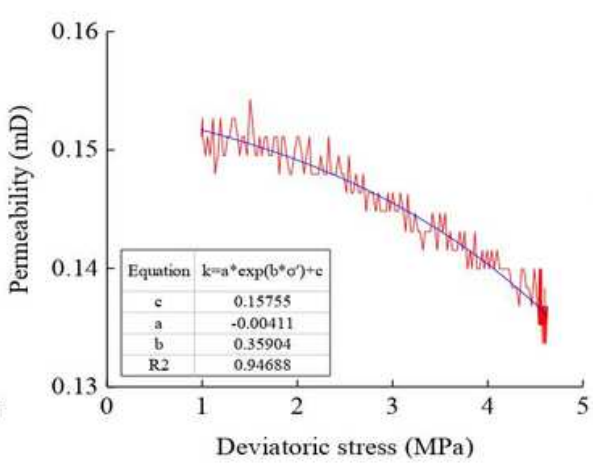

(b) $\sigma_{1}: 7.0 \rightarrow 10.63$

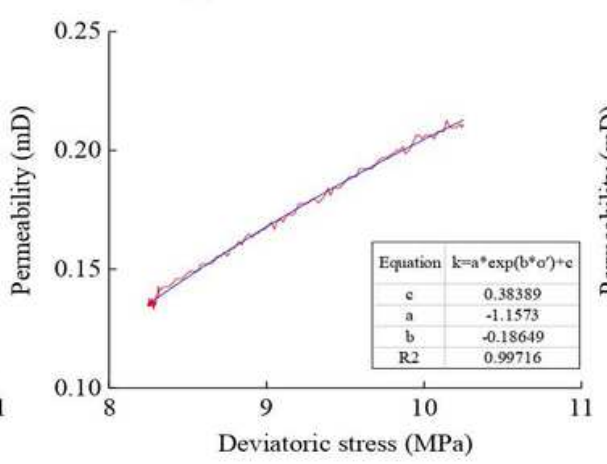

(e) $\sigma_{3}: 4.6 \rightarrow 6.0$

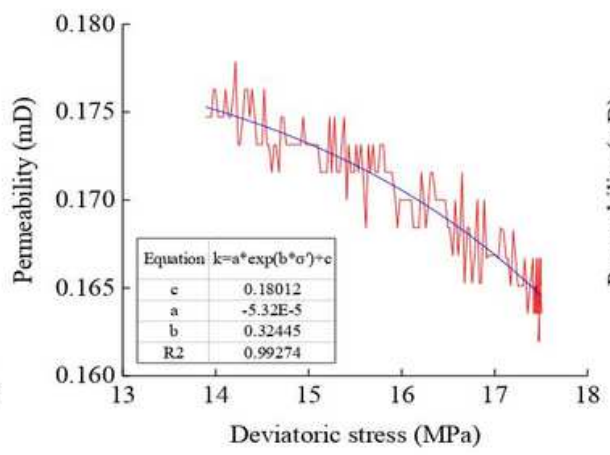

(h) $\sigma_{1}: 17.88 \rightarrow 21.5$

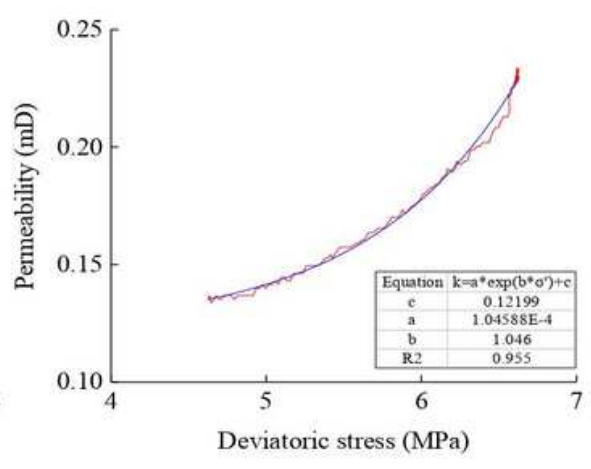

(c) $\sigma_{3}: 6.0 \rightarrow 4.0$

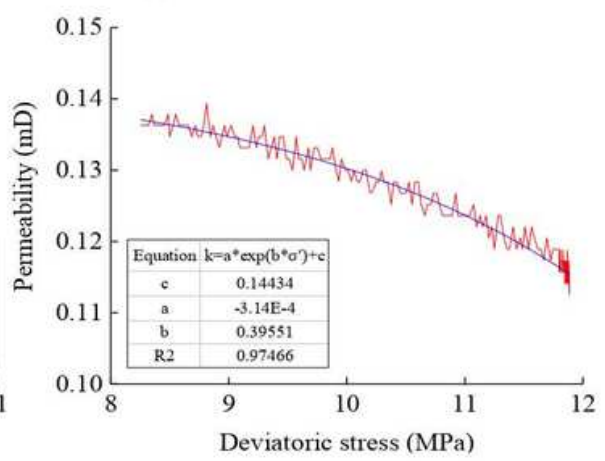

(f) $\sigma_{1}: 14.25 \rightarrow 17.88$

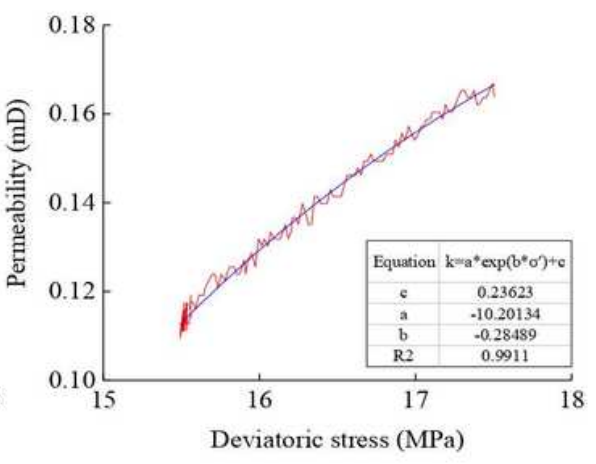

(i) $\sigma_{3}: 4.6 \rightarrow 6.0$

\section{Figure 5}

Relationship curve between permeability of sample a1 and deviatoric stress during loading-unloading 